\title{
The financial market effects of international aviation disasters
}

\author{
Erdinc Akyildirim ${ }^{\mathrm{a}}$, Shaen Corbet ${ }^{\mathrm{b}, \mathrm{c}, *}$, Marina Efthymiou ${ }^{\mathrm{b}}$, Cathal Guiomard ${ }^{\mathrm{b}}$, John F. O'Connell ${ }^{\mathrm{d}}$, \\ Ahmet Sensoy \\ ${ }^{a}$ Department of Banking and Finance, University of Zurich, Zurich, Switzerland \\ ${ }^{\mathrm{b}}$ DCU Business School, Dublin City University, Dublin 9, Ireland \\ ${ }^{\mathrm{c}}$ School of Accounting, Finance and Economics, University of Waikato, New Zealand \\ d Centre of Aviation Research, School of Hospitality and Tourism Management, University of Surrey, UK \\ ${ }^{\mathrm{e}}$ Bilkent University, Faculty of Business Administration, Ankara 06800, Turkey
}

\section{A R T I C L E IN F O}

\section{Keywords:}

Airline disaster

Contagion

Volatility

Reputation risk

Financial markets

\begin{abstract}
A B S T R A C T
The spread of misinformation with regards to aviation disasters continues to be a point of concern for aviation companies. Much of this information usually surrounds speculation based on the cause and responsibility attributed to the incident, implicitly possessing the potential to generate significant financial market price volatility. In this paper, we investigate a number of stylised facts relating to the effects of airline disasters on aviation stocks, while considering contagion effects, information flows and the sources of price discovery within the broad sector. Results indicate a substantially elevated levels of share price volatility in the aftermath of aviation disasters, while cumulative abnormal returns present sharp under-performance of the analysed companies relative to international exchanges. When considering an EGARCH analysis, we observe that share price volatility appears to be significantly influenced by the scale of the disaster in terms of the fatalities generated. Significant contagion effects upon the broad aviation index along with substantial changes in traditional price discovery channels are also identified. The role that the spread of information on social media, whether it be correct or of malicious origins, cannot be eliminated as an explanatory factor of these changing dynamics over time and region.
\end{abstract}

\section{Introduction}

The aviation sector has been exposed to a number of quite unique threats in recent years, while further experiencing some exceptionally rare events that few other industries must contest. The sector has been directly exposed to elevated threats of terrorism, with the most devastating events occurring in the United States in 2001 (Kim \& Gu, 2004), resulting in widespread industrial reform and increased running costs. However, some incidents have been mostly as a result of exception unfortunate circumstance. For example, one of the most rare events involved that of Malaysia Airlines, who during an unprecedented turn of events, lost two commercial airliners within five months in 2014, leading to the subsequent nationalisation of the company so that government could protect both the Malaysian tourism industry and attempt to ensure the employment of almost twenty thousand employees that relied on the company's survival. Kaplanski and Levy (2010) found that in the aftermath of a significant negative event effect with an average market loss of more than $\$ 60$ billion per aviation disaster, whereas the estimated actual loss is no more than $\$ 1$ billion, where within two days after the event, a price reversal occurs. Understanding the dynamics of financial market behaviour and the manner in which investors perceive such risk is of the utmost importance for companies who have been unfortunate enough to experience such disasters. What is already considered to be deeply competitive industry generates substantial pressures on aviation companies with little scope allowed for error. Such pressures can manifest in exceptional industrial and managerial pressures to perform in line with industry expectations.

Although airline accidents are infrequent, they can have significant effects on an airline's stock price and profitability (Borenstein \& Zimmerman, 1988; Li, Phun, Suzuki, \& Yai, 2015). Chance and Ferris (1987) found that the financial impact of an aviation disaster is focused solely on the carrier, while the industry as a whole is not affected. Noronha and Singal (2004) investigated 783 accidents/incidents of US domiciled airlines and found that only about $2-3 \%$ were serious enough to cause financial pain. They also concluded that the investment bond credit rating would change by a whole 'letter' change, for example from $\mathrm{AAA}$ to $\mathrm{AA}+$ as a result of this serious accident. Both Borenstein and Zimmerman (1988) together with Mitchell and Maloney (1989)

\footnotetext{
* Corresponding author at: DCU Business School, Dublin City University, Dublin 9, Ireland.

E-mail address: shaen.corbet@dcu.ie (S. Corbet).
} 
analysed changes in equity value following accidents and found evidence that airlines which experienced fatal accidents were subsequently penalised by modest profitability declines. Ho, Qiu, and Tang (2013) examined the impact of aviation tragedies on the stock prices of the airlines that had encountered a crash together with their rival carriers and found that the afflicted airline experienced deeper negative abnormal returns as the degree of fatality increases. However, stock prices of the rival airlines also suffer in large-scale disasters but benefit somewhat from the disasters when the fatality is minor. Walker, Thiengtham, and Lin (2005) employed a sample of 138 aviation disasters involving aircraft operated by publicly traded US carriers between July 1962 and December 2003. The authors observed that airlines experience an average stock price drop of $2.8 \%$ within one trading day after the corresponding news announcement, while aircraft manufacturers experienced a stock price drop of only $0.8 \%$ during that time period. Similarly, Barrett, Heuson, Kolb, and Schropp (1987) concur by calculating that the average market decline for airline stock prices within a day of the crash is approximately $1.5 \%$. The magnitude of the initial price decline appears to be driven by various characteristics of both the firm and the accident itself. It is important to note that some research has pointed to sectoral financial difficulty, such as that of Assaf (2009) who identified through a technical model that US airlines are operating at a declining efficiency rate with an average of $69.02 \%$ in 2007 , with results from returns to scale also echoing efficiency results. Lee and Jang (2007) found that through an analysis of 16 airline companies for the period of 1997-2002, profitability, growth and safety are negatively associated with the systematic risk, while the debt leverage and firm size are positively related to the risk. This risk has been exacerbated somewhat by substantial increases in competition over time (Francis, Dennis, Ison, \& Humphreys, 2007).

Research relating to aviation disasters has a number of relevant policy implications. Market sensitivity to such sudden, catastrophic shocks could be deeply exacerbated by the role of social media and the spread of misinformation, or malicious information in the aftermath of such events. Much of the spread of such information usually surrounds speculation based on the cause and responsibility attributed to the incident. While we must consider that financial markets in recent years are guided by a more rapid dissemination of information through the development of social media which could be perceived to be of better quality through the ease through which pictures and videos are shared through which observers can make their own opinion, it should also be considered that the presence of such improved efficiency could in fact manifest in side-effects such as an ability to profit from the spread of false information, not only generating further undue distress on the companies and families involved in such tragedy, but also hindering the efforts of rescue teams while further inspiring other market participants who do not fear current regulatory and policing efforts.

In this paper, we investigate as to whether a number of stylised facts relating to the effects of airline disasters on aviation stocks and contagion effects within the broad sector hold. First, we analyse as to whether there exist time-varying and geographical differences in the response mechanisms of investors to aviation disasters, or indeed, has there been a variation of response that could be considered to be correlated to the level of injury and fatality caused by each individual incident. Further, we generate further novelty through the inclusion of analysis that focused on the interlinkages between the incident companies and the broad aviation sector. Finally, we investigate changes in flow of information and price discovery that could be considered to be abnormal when considering pre-disaster averages between the stock price of incident companies and broad aviation indices that represent sectoral returns.

We first clearly identify that substantially elevated levels of share price volatility, however, there is evidence to suggest that this volatility has somewhat decreased in the periods 2005 through 2019. Such effects are found to be substantial when considering geographical differentials, with both North American and South American companies exhibiting the largest negative effects. When analysing cumulative abnormal returns (CARs), we observe that there exists sharp under-performance of the companies relative to international exchanges throughout each of the analysed time periods with the exception of the period between 2000 and 2004. When considering an EGARCH analysis to investigate specific volatility effects, we observe a sharp increase in unconditional volatility in the ten-day period after the aviation incident, indicative of strong short-term effects. However, while the shock to unconditional volatility appears to be immediate, there is evidence to suggest that it dissipates and returns to pre-aviation incident levels within sixty days after the event. Further, our results indicate that there exists a clear positive relationship between the two variables, indicating that the estimated EGARCH-volatility appears to be significantly influenced by the scale of the disaster in terms of the fatalities generated. When considering the contagion effects of volatility and the flow of information and price discovery between the incident company and the broad aviation sector, we find that there were substantial decreased in dynamic conditional correlations during incidents that occurred in the periods 1995-99, 2000-04 and 2005-09 respectively. However,evidence of such pronounced effects do not appear to occur in the periods between 2010 and 14 and 2015-19. For every case analysed we find that there were substantial decreases in information flow identified between the interactions between both the airline and the aviation sector. This indicates that there is a permanent disruption to the flow of information and price discovery channels that would have traditional have existed in the period prior to the aviation disaster.

The rest of this paper is as follows. Section 2 presents a thorough review of the literature relating to the interlinkages between aviation disasters and the varying effects on financial markets and sectoral interactions. Section 3 presents a concise overview of the data used in this research along with the various methodologies employed to capture firm-level volatility, both intra-sectoral and geographic volatility transmission, and indeed contagion effects by type of aviation incident. Section 4 presents a concise overview of the results presented, while Section 5 concludes.

\section{Previous literature}

Although much research focuses specifically on the aviation sector in terms of structure and performance, little has focused specifically on the presence of sectoral interactions between rival and geographicallysimilar aviation companies. Research of such nature is of substantial value to the broad sectoral correlations that exist, enabling theoretically-plausible avenues through which large aviation incidents could generate significant sector-wide risk. While this research sets out to investigate the existence of such channels as identified by stock market dynamics, it builds on a number of existing research areas. Chance and Ferris (1987) found that such incidents were, in the mid-1980s ringfenced from the broad sector at large, however, much research today has begun to focus on the dissemination of news through multiple technological channels, leading to quite strong theoretical foundations to signal that such results might not exist almost three decades later. Ho et al. (2013) found that there do exist abnormal returns in competitor companies during major sectoral incidents, however, their share price is found to otherwise increase should the incident be considered minor. This research does not extend its scope beyond abnormal pricing, however, the sentiment of the results further indicate that the work of Chance and Ferris (1987) might not represent the industry today. Kaplanski and Levy (2010) analysed the influence of aviation disasters on stock prices while considering the role of sentiment. Should a market loss of more than US\$60 million, the authors identify evidence of substantial negative stock market responses, increased perceived risk and implied volatility, despite no evidence of an increase in actual volatility. Such a result is, of course, not limited to the aviation sector. Carpentier and Suret (2015) found that such losses exist across a broad number of major accidents, however, they do not persist. Ho et al. 
Table 1

Summary statistics of analysed traded airlines.

\begin{tabular}{|c|c|c|c|c|c|c|c|c|}
\hline & DJIA & WTI & AVI & AFLT & LT & AEROMEX & AC.TO & AIRF.PA \\
\hline Mean & 0.0003 & 0.0002 & 0.0005 & 0.0000 & 0.0008 & -0.0002 & 0.0002 & -0.0002 \\
\hline Std. Dev. & 0.0108 & 0.023 & 0.0115 & 0.0189 & 0.1047 & 0.0165 & 0.0353 & 0.0310 \\
\hline Minimum & -0.0820 & -0.1654 & -0.0751 & -0.1779 & -5.4381 & -0.1037 & -0.3465 & -0.3510 \\
\hline Median & 0.0003 & 0.0000 & 0.0007 & 0.0000 & 0.0000 & 0.0000 & 0.0000 & 0.0000 \\
\hline Maximum & 0.1051 & 0.1641 & 0.1028 & 0.1552 & 4.8675 & 0.2869 & 0.3983 & 0.5996 \\
\hline Skewness & -0.1925 & -0.0773 & -0.1486 & 0.1031 & -7.4295 & 2.71 & -0.1579 & 0.6207 \\
\hline Kurtosis & 11.4064 & 7.3101 & 9.1538 & 10.1885 & 2266.2442 & 52.7834 & 20.6945 & 40.2413 \\
\hline Jarque Bera & $18,786.8^{* * *}$ & $4934.8^{* * *}$ & $10,069.8^{* * *}$ & $8117.5^{* * *}$ & $24,387,646.1^{* * *}$ & $221,518.9 * * *$ & $42,659.6 * * *$ & $366,494.8^{* * *}$ \\
\hline \multirow[t]{2}{*}{$\mathrm{ADF}$} & $-84.1535^{* * *}$ & $-81.6929 * * *$ & $-71.6901 * * *$ & $-65.7135^{* * *}$ & $-72.1191^{* * *}$ & $-47.2714^{* * *}$ & $-50.5512^{* * *}$ & $-76.4258^{* *}$ \\
\hline & ALK & 020560.KS & BA & 2610.TW & $600,029 . S S$ & COMJ.J & UAL.O & DAL \\
\hline Mean & 0.0004 & 0.0000 & 0.0000 & -0.0002 & 0.0002 & 0.0001 & 0.0002 & 0.0003 \\
\hline Std. Dev. & 0.0269 & 0.0287 & 0.0217 & 0.0209 & 0.0284 & 0.0339 & 0.0405 & 0.0328 \\
\hline Minimum & -0.3364 & -0.1713 & -0.2384 & -0.099 & -0.1058 & -0.2955 & -0.4584 & -0.2374 \\
\hline Median & 0.0000 & 0.0000 & 0.0000 & 0.0000 & 0.0000 & 0.0000 & 0.0000 & 0.0000 \\
\hline Maximum & 0.2722 & 0.2624 & 0.1568 & 0.1054 & 0.0963 & 0.3208 & 0.522 & 0.2355 \\
\hline Skewness & -0.1714 & 0.422 & -0.18 & 0.0842 & -0.0537 & 0.0652 & -0.0227 & -0.1072 \\
\hline Kurtosis & 14.1765 & 10.0078 & 11.1471 & 5.5098 & 5.8805 & 12.7829 & 25.6682 & 11.4603 \\
\hline Jarque Bera & $33,170.1 * * *$ & $10,522.7^{* * *}$ & $17,643.2^{* * *}$ & $1678.1^{* * *}$ & $1431.2^{* * *}$ & $21,701^{* * *}$ & $74,529.4 * * *$ & $9415.4^{* * *}$ \\
\hline \multirow[t]{2}{*}{$\mathrm{ADF}$} & $-82.9115^{* * *}$ & $-66.3049^{* * *}$ & $-76.1207^{* * *}$ & $-78.4393^{* * *}$ & $-58.9574 * * *$ & $-80.8645^{* * *}$ & $-54.9817^{* * *}$ & $-55.5217^{* * *}$ \\
\hline & GIAA.JK & KQNA.NR & 003490.KS & PIAa.KA & SAS.ST & SIAL.SL & LUV & THAI.BK \\
\hline Mean & -0.0002 & -0.0008 & 0.0001 & -0.0001 & -0.0006 & 0.0000 & 0.0004 & -0.0003 \\
\hline Std. Dev. & 0.023 & 0.0376 & 0.0312 & 0.0379 & 0.0313 & 0.0167 & 0.0223 & 0.0289 \\
\hline Minimum & -0.1467 & -1.8589 & -0.1625 & -0.3656 & -0.3291 & -0.1295 & -0.2753 & -0.2204 \\
\hline Median & 0.0000 & 0.0000 & 0.0000 & 0.0000 & 0.0000 & 0.0000 & 0.0000 & 0.0000 \\
\hline Maximum & 0.174 & 0.1209 & 0.2252 & 0.3733 & 0.2821 & 0.1437 & 0.1576 & 0.257 \\
\hline Skewness & 1.0895 & -27.1798 & 0.2564 & 0.7466 & 0.1416 & 0.1527 & -0.3554 & 0.4672 \\
\hline Kurtosis & 9.562 & 1301.0383 & 7.1936 & 12.2007 & 13.611 & 9.4477 & 10.6379 & 10.087 \\
\hline Jarque Bera & $4310.7^{* * *}$ & $328,851,069.6 * * *$ & $4735.3^{* * *}$ & $23,042^{* * *}$ & $21,919.6^{* * *}$ & $11,053.5^{* * *}$ & $15,610.6^{* * *}$ & $13,555.9^{* * *}$ \\
\hline \multirow[t]{2}{*}{$\mathrm{ADF}$} & $-48.0585^{* * *}$ & $-62.847^{* * *}$ & $-74.1804^{* * *}$ & $-80.6308^{* * *}$ & $\quad-66.1177^{* * *}$ & $-83.2529 * * *$ & $-86.4308^{* * *}$ & $-79.9079 * * *$ \\
\hline & THYAO.IS & UTAR.MM & MASM & AIRA.KL & LTM.SN & LHAG.DE & SEBF.PA & SIAL.SI \\
\hline Mean & 0.0009 & 0.0003 & -0.0004 & 0.0002 & 0.0004 & 0.0001 & 0.0003 & 0.0000 \\
\hline Std. Dev. & 0.0341 & 0.0421 & 0.025 & 0.0217 & 0.02 & 0.0212 & 0.0201 & 0.0167 \\
\hline Minimum & -0.202 & -0.7366 & -0.5051 & -0.1364 & -0.1773 & -0.1636 & -0.1697 & -0.1295 \\
\hline Median & 0.0000 & 0.0000 & 0.0000 & 0.0000 & 0.0000 & 0.0000 & 0.0000 & 0.0000 \\
\hline Maximum & 0.1796 & 1.772 & 0.2877 & 0.1281 & 0.1823 & 0.1571 & 0.1617 & 0.1437 \\
\hline Skewness & 0.3318 & 15.4432 & -0.7642 & 0.1939 & 0.351 & -0.1347 & 0.1246 & 0.1527 \\
\hline Kurtosis & 7.7116 & 709.5296 & 40.1085 & 7.1934 & 13.1096 & 6.9893 & 8.3459 & 9.4477 \\
\hline Jarque Bera & $6006.1 * * *$ & $99,381,603.3^{* * *}$ & $365,937.4^{* * *}$ & $2799.2^{* * *}$ & $26,213.2^{* * *}$ & $4241.3^{* * *}$ & $7598.1 * * *$ & $11,053.5^{* * *}$ \\
\hline $\mathrm{ADF}$ & $-78.8869^{* * *}$ & $-65.7303^{* * *}$ & $-81.0661^{* * *}$ & $-59.4133^{* * *}$ & $-66.4438^{* * *}$ & $-77.8715^{* * *}$ & $-80.2885^{* * *}$ & $-83.2529 * * *$ \\
\hline
\end{tabular}

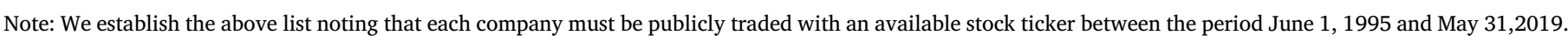

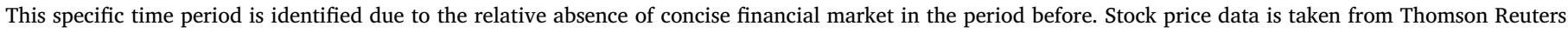
Eikon.

(2013) found that airlines that suffer a crash experience deeper negative abnormal returns as the degree of fatality increases, but also, the stock prices of the rival airlines also suffer in large-scale disasters but benefit from the disasters when the fatality is minor. Hung and Liu (2005) use the beta value, an indicator of systematic risk, to estimate the costs of equity and the evaluation of a stock's reasonable price, to find that airline betas are volatile over time and that crashes also impact them in addition to their stock return and volatility.

Outside of just stock market performance in isolation, there might exist channels through which corporate effects can also be transferred to airlines companies. While legal liability, broad reputational damage and the loss of equipment can be found to explain a substantial amount of the target company's losses, guided by the work of Walker, Walker, Thiengtham, and Pukthuanthong (2014) found that there are a number of regulatory factors that extend far beyond insurance premiums and reputational damage. Dillon, Johnson, and Pate-Cornell (1999) identified evidence to suggest that in the aftermath of a single aviation incident, shareholders appear to update their estimates of the probability of a future incident, acting as an explanation for the substantial cumulative abnormal returns that exist. Exogenous events might also have such negative outcomes. For example, Corbet, O'Connell, Efthymiou, Guiomard, and Lucey (2019) found that traffic flows fall quite sharply despite significant fare reductions as a result of terrorist incidents in Europe. Such terrorism impacts were also found to be both significant and substantial when considering the persistence of their effects at both sectoral and national levels (Carter \& Simkins, 2004; Corbet, Gurdgiev, \& Meegan, 2018; Kim \& Gu, 2004; Kolaric \& Schiereck, 2016). Carvalho, Klagge, and Moench (2011) analysed the 2008 case where an six-year old article based on the bankruptcy of United Airline's parent company was mistakenly identified as a new bankruptcy filing, causing a $76 \%$ fall in the company's share price, but after the case was identified as an error, the stock remained over $11 \%$ below opening prices, as the authors identify that contagion effects would dominated competitive effects. Luo (2007) used longitudinal real-world data set that matches consumer negative voice (complaint records) in the airline industry with firm stock prices, this article finds that higher levels of current 
a) Total number of incidents by quarter

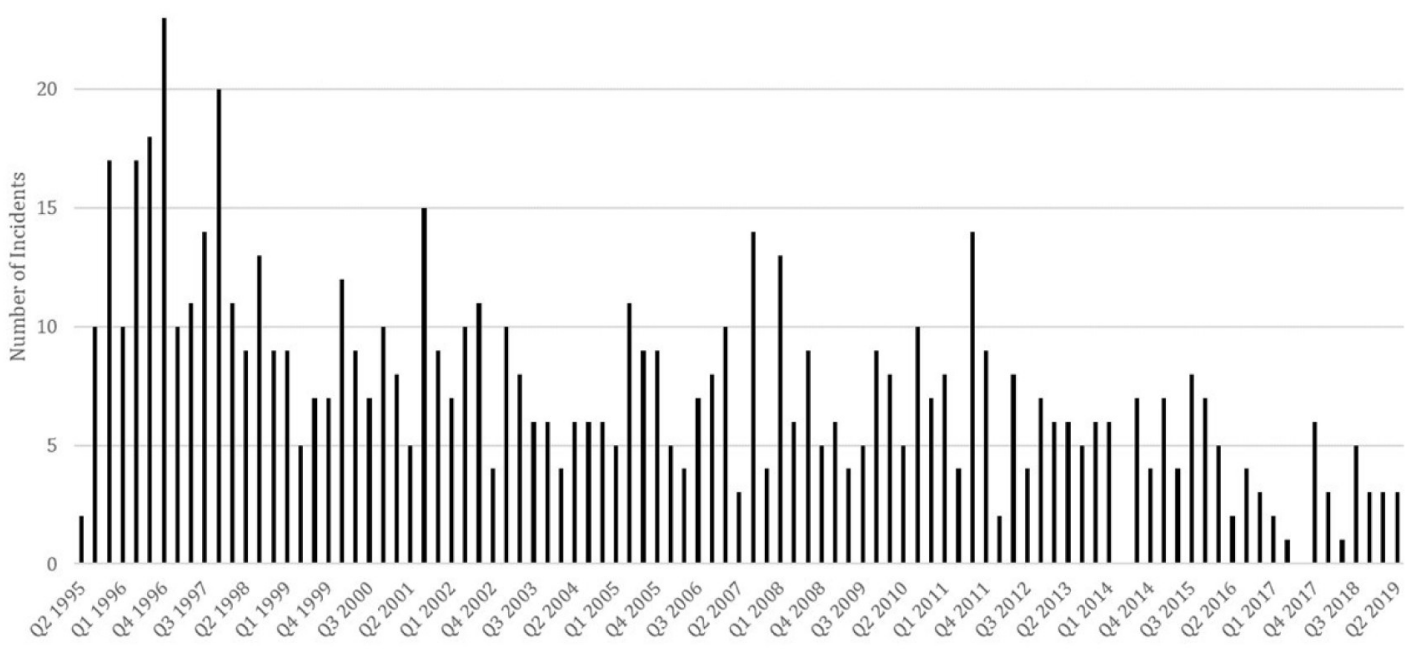

b) Total number of fatalities by quarter

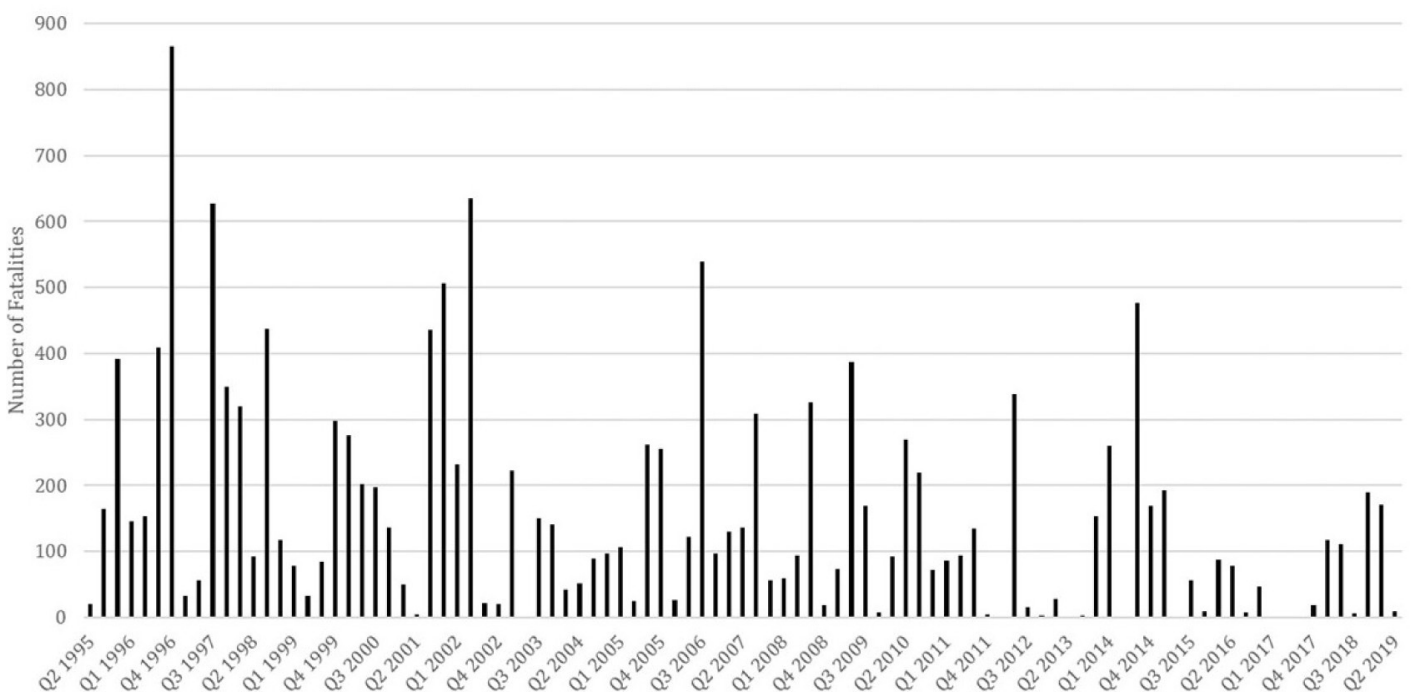

Fig. 1. Cumulative number of incidents and fatalities of traded airlines, by quarter, Q2 1995 through Q2 2019.

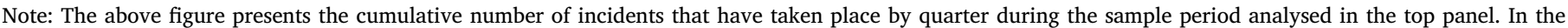
bottom panel, we find the estimates of the total number of fatalities by quarter analysed.

consumer negative voice harm firms' future idiosyncratic stock returns.

Since energy commodities play an important role for the airlines industry, their price fluctuations can also create problems for aviation stocks in financial markets. Treanor, Rogers, Carter, and Simkins (2014) found that airlines that increase their hedging activity due to higher fuel price exposure are not receive a premium in their valuation when compared to those airlines employing more stable hedging policies. However, Berghofer and Lucey (2014) found that there exists less significant negative exposure coefficients among US carriers. Yun and Yoon (2019) found that there is a return and volatility spillover effect between crude oil price and the stock prices of airlines and that the stock prices of smaller airlines of South Korea and China are relatively more sensitive to the change in oil price. Kristjanpoller and Concha (2016) found a strong positive influence of fuel price fluctuation and airline stock returns using GARCH-family methodologies.

\section{Data and methodology}

\subsection{Data}

We begin our analysis developing a concise list of aviation disasters that can then be utilised in a thorough and robust methodological investigation through an analysis of parent companies who trade on stock markets and their subsequent performance. Broad speculation based on the cause of such an airline disaster can manifest through many forms, but direct financial punishment due to investor perceptions can present a number of damaging side-effects for the broad aviation sector. To develop such a dataset, we develop a number of strict rules in an attempt to standardise the process across major international financial markets. The first implemented rule is that the specified company must be a publicly traded company with an available stock ticker between the period June 1, 1995 and May 31, 2019. This specific time period is identified due to the relative absence of concise financial market in the period before. Our selected stock price data is taken from Thomson Reuters Eikon. The second news selection rule is based on the source of the aviation disaster data. We develop on a combined search of LexisNexis, Bloomberg and Thomson Reuters Eikon, search for the keywords relating to aviation disasters. For added robustness of our developed dataset, we leverage upon that of the National Transportation Safety Board (available at: https://www.ntsb.gov), the International Civil Aviation Organization, ICAO (available at: https:// www.icao.int) and the Aviation Safety Reporting System (available at: 
a) Geographic dispersion based on domicile country of the traded country

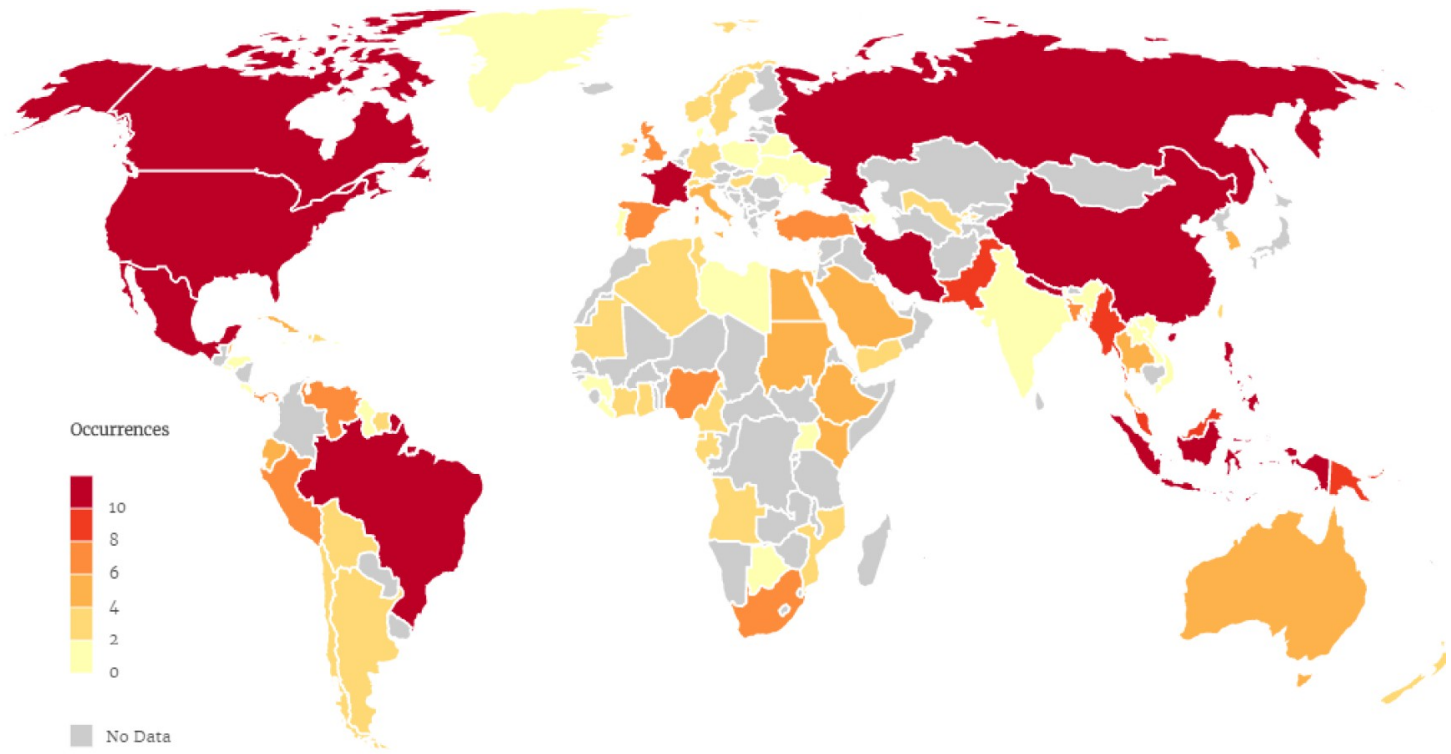

b) Geographic dispersion based on incident country

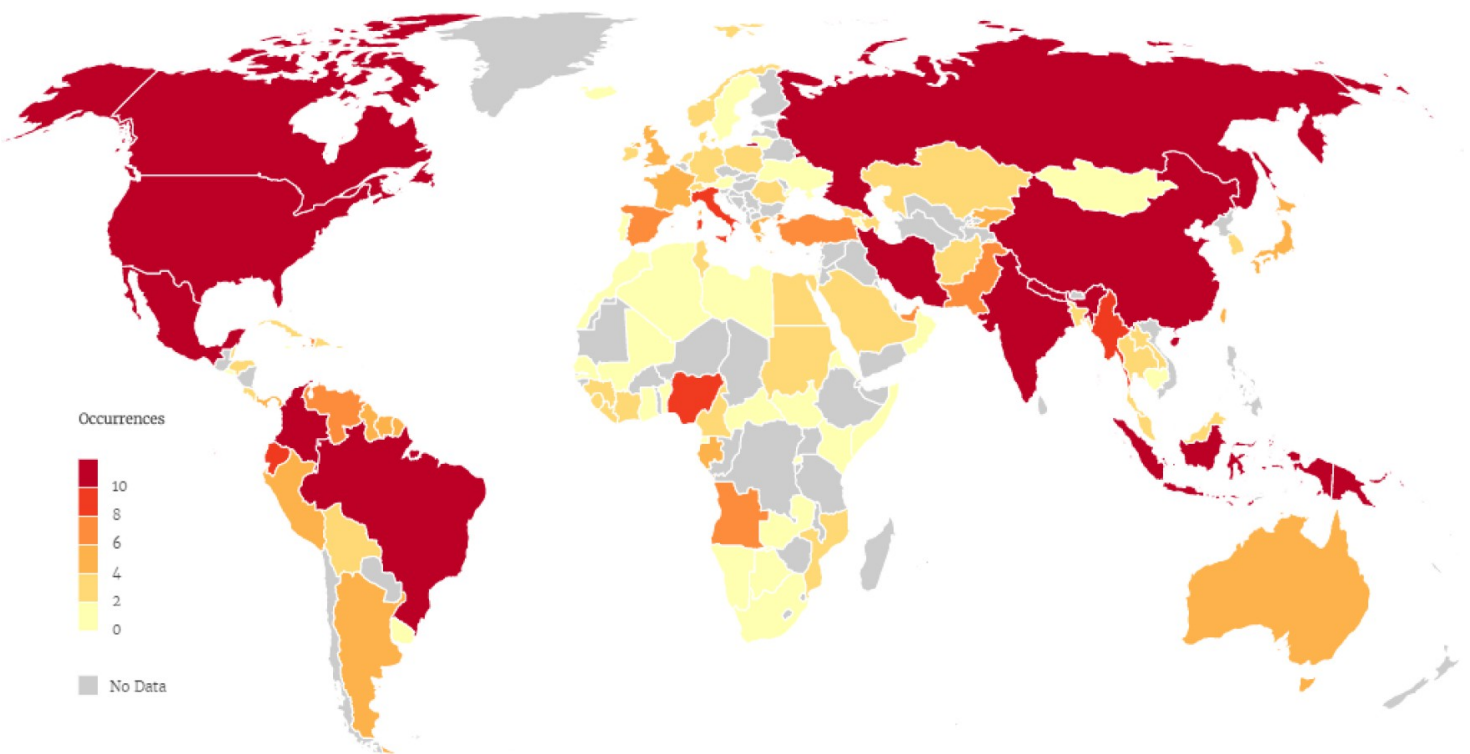

Fig. 2. Geographic dispersion of incidents as denoted by domicile country of traded company.

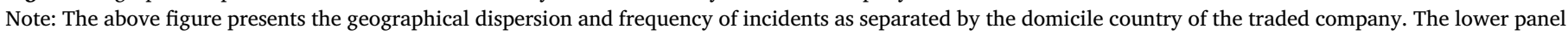
presents the geographic dispersion of incidents as separated by crash site.

https://asrs.arc.nasa.gov).

To obtain a viable observation, a single result must be present across each of the selected search engines and the source was denoted as an international news agency, a mainstream domestic news agency or the company making the announcement itself. Forums, social media and bespoke news websites were omitted from the search. Finally, the selected observation is based solely on the confirmed news announcements being made on the same day across all of the selected sources. If a confirmed article or news release had a varying date of release, it was omitted due to this associated ambiguity. All observations found to be made on either a Saturday or Sunday are denoted as active on the following Monday morning. All times are adjusted to GMT, with the official end of day closing price treated as the listed observation for each comparable company when analysing associated contagion effects. In Table 1 we observe the relevant summary statistics for the included aviation companies that experienced severe aviation disasters throughout the time period analysed.

In Fig. 1, we observe the cumulative number of incidents and fatalities that occurred on a quarterly basis between Q2 1995 and Q2 2019. There is evidence of a decline in both estimates, with peaks experienced throughout the period between Q1 1996 and Q4 1996. In total, there are 610 incidents included in our analysis, of which there were 12,692 fatalities. The worst incidents include that of the crash of a Saudi Arabian Airlines Boeing 747-100 in New Delhi in November 1996, which led to the death of 312 people. Further, in the 11 September terrorist attacks of 2001, the Airbus A300-600 that crashed in New York leading to the deaths of 262 persons is also included among the worst incidents included in the database. The second and fourth most severe incidents included unfortunately involve the same company, Malaysia Airlines. In 2014, an idiosyncratic succession of accidents, unparalleled in aviation history unfolded within a five month time frame as two widebody aircraft operated by Malaysia Airlines 
a) $1995-1999$

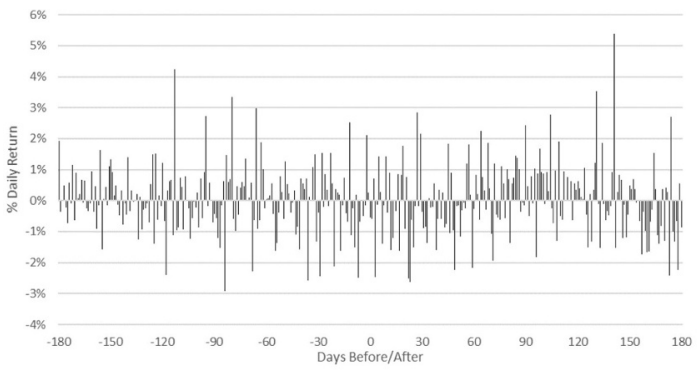

c) $2005-2009$

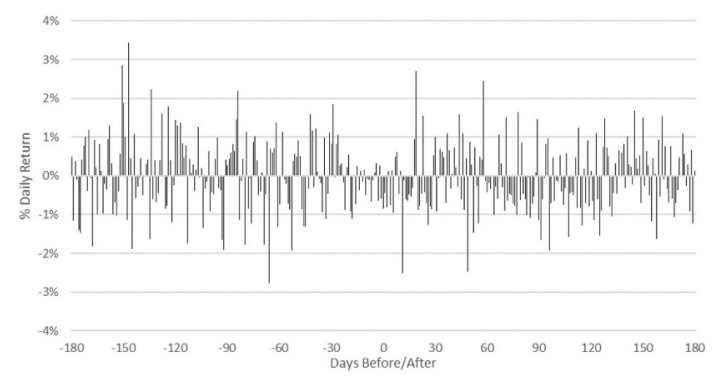

b) $2000-2004$

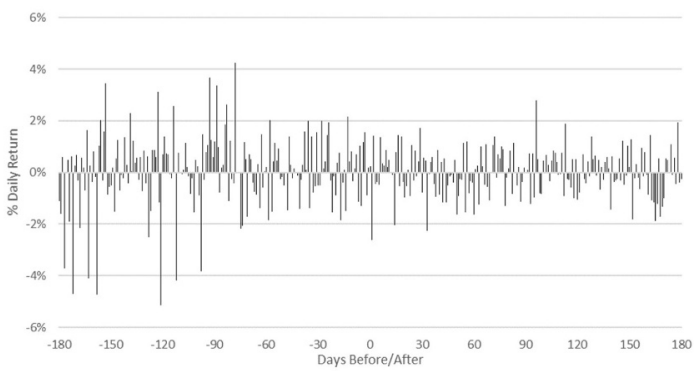

d) $2010-2014$

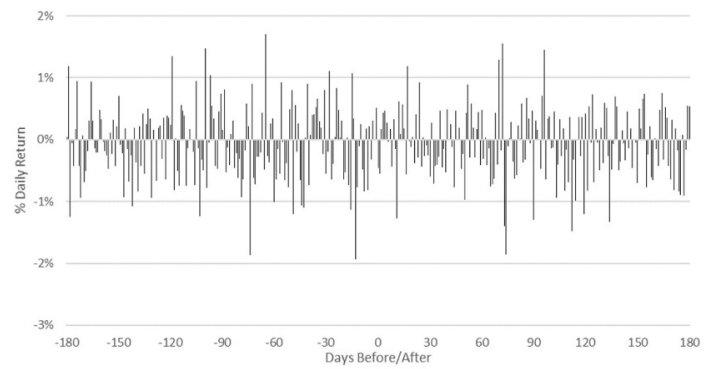

e) $2015-2019$

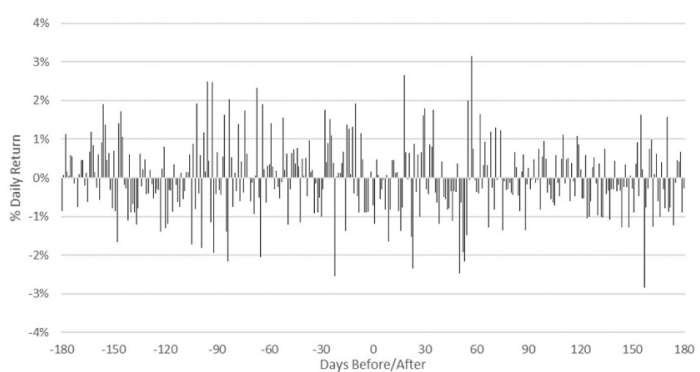

Fig. 3. Share price volatility response over time due to airline disasters (1995-2019).

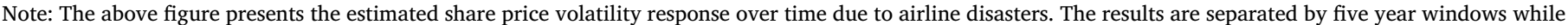
presenting the average results for sixty days both before and after each incident for presentation purposes.

crashed under inconceivable circumstances. The first tragedy to strike Malaysia Airlines was the loss of flight MH370, which disappeared while flying from Kuala Lumpur International Airport to Beijing Capital International Airport on 8 March 2014 with the loss of 227 passengers and 12 crew. Inmarsat satellites identified two potential trajectories, that MH370 could have taken, but after much analysis the investigators speculated with a high degree of probability that the perilous aircraft was navigated along a southern trajectory, leading it deep into the southern Indian Ocean. After one of the most expensive searches in aviation history, the aircraft has not been found, however several pieces of debris washed ashore in the western Indian Ocean during 2015 and 2016 which were confirmed to be from the airliner. In the aftermath of the loss of MH370, Malaysia Airlines were then subjected to their second significant loss as MH17, a scheduled flight from Amsterdam to Kuala Lumpur that was shot down on 17 July 2014 while flying over eastern Ukraine, where an armed conflict broke out in April 2014. Flights over the conflict zone were allowed as there was no indication of risk for civil aeroplanes at cruising altitude and Malaysia Airlines, as almost all airlines, assumed that the airspace is safe. A Buk 9 M38-series surface-to-air missile with a $9 \mathrm{~N} 314 \mathrm{M}$ warhead was found to have downed the aircraft. An explosive decompression resulted in the disintegration of the aircraft while in-flight and all 283 passengers together with 15 crew members perished resulting in a wreckage area of 50 square $\mathrm{km}$ on the ground. The four most severe incidents in this sample account for 1111 fatalities in the sample. In Fig. 2 we identify the geographic dispersion of first, incidents as denoted by the geographic dispersion of the parent companies of the airlines that have experienced the aviation disaster. The second panel displays the geographic dispersion of the analysed incidents within this research. It is of interest to note that a large number of African nations and countries such as Bangladesh, India, Nepal and Colombia have experienced a broad number of aviation disasters in their respective nations, however, there are few incidents recorded in our dataset that include airlines from these regions that are publicly traded.

\subsection{Methodology}

To further the development of our understanding of disasters within the aviation sector, we set out to first specifically analyse the immediate pricing and volatility effects on the stock prices of the company that owned the plane that has been lost. To add methodological robustness to our selected analysis, we have utilised a number of GARCH-family methodologies $^{1}$ while we further attempt to mitigate international

\footnotetext{
${ }^{1}$ The analysed specifications included EGARCH, GJR-GARCH, TGARCH, Asymmetric Power ARCH (APARCH), Component GARCH (CGARCH) and the Asymmetric Component GARCH (ACGARCH), with the best selected methodology based on standard goodness-of-fit criteria such as the Akaike information criterion, Bayesian information criterion (BIC), Shibata Information
} 
a) Africa

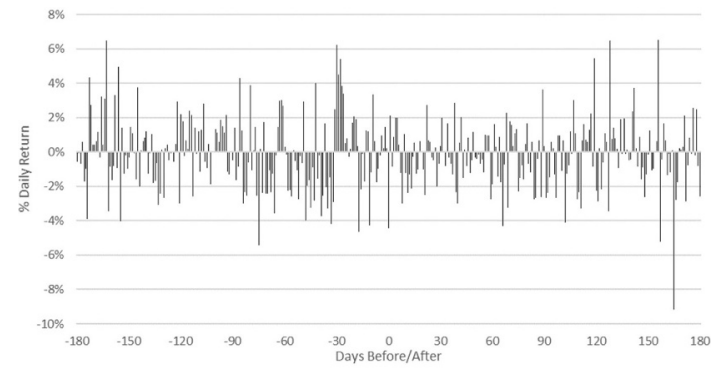

c) Europe

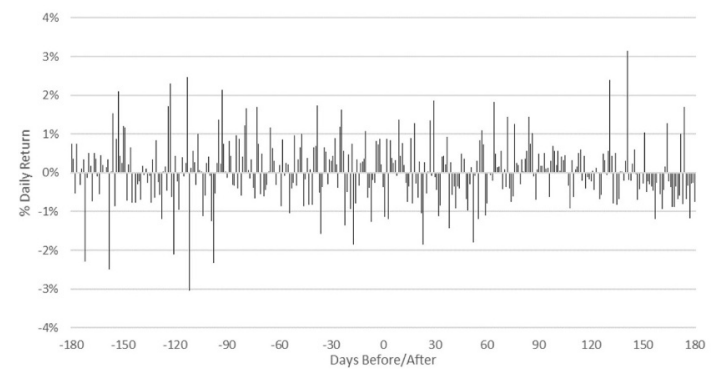

b) Asia

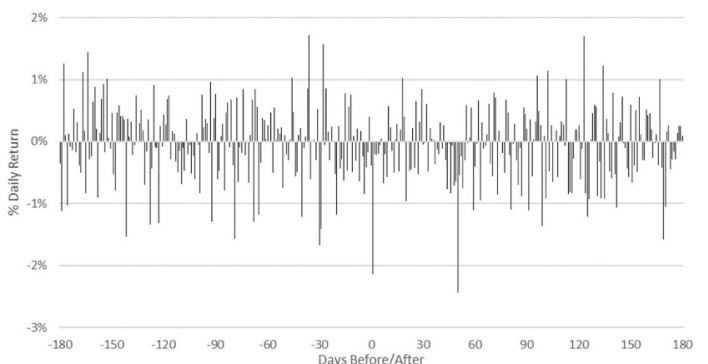

d) North America

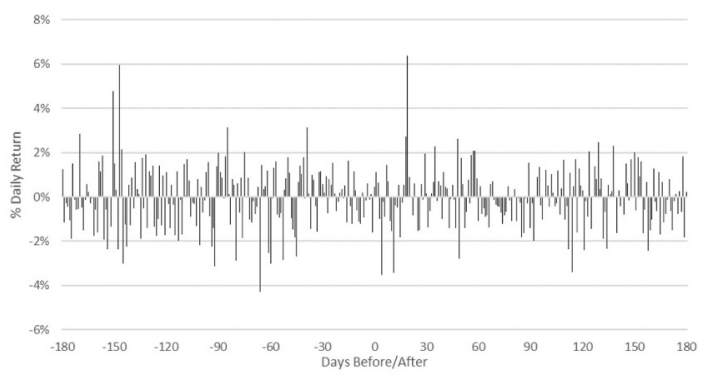

South America

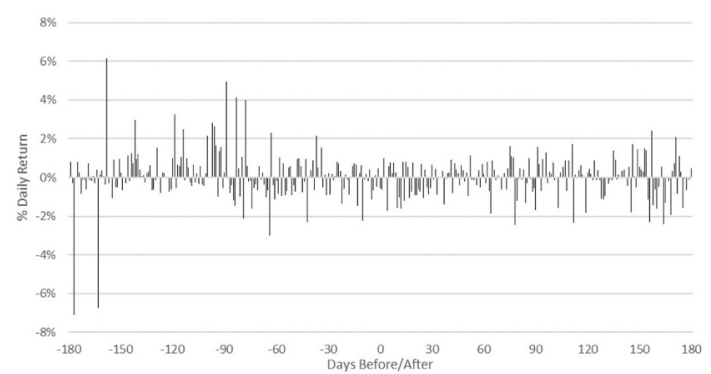

Fig. 4. Share price volatility response by region due to airline disasters.

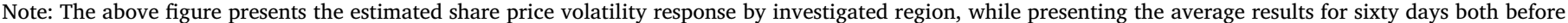
and after each incident for presentation purposes.

factors through the inclusion of the Dow Jones Industrial Average (DJIA), West Texas Intermediate oil prices (WTI) and the SPDR S\&P Transportation ETF (XTN) which is found to best represent the performance of aviation companies during the period analysed. We further consider as to whether such volatility effect has changed in the period since the broad growth. In a secondary analysis, we then investigate the relationship between each company and the broad measure of the aviation index through the use of a DCC-GARCH analysis. It has been widely considered that some specific accidents have been large enough to generate substantial reverberations throughout the entire sector due to the presence of a number of technical and regulatory mishaps (Ho et al., 2013; Krieger \& Chen, 2015; Nethercutt \& Pruitt, 1997). Such dynamics could be attributed to the market expectations that future regulatory changes could be forthcoming and could even perhaps be restrictive to the future profitability of the sector. Finally, to validate and add further robustness to the presented results, we investigate the sources of price discovery in the relationship between the broad sectoral indices and the companies that have experienced such substantial loss and reputational damage in an attempt to further analyse investor behaviour. We define a distressed airline company as that which has experienced a substantial tragedy in the form of the loss of a plane.

(footnote continued)

Criterion and the Hannan-Quinn information criterion.
Overall, there are a number of specific questions that we then set out to analyse.

- $H_{1}$ : Has the price response of distressed airline companies varied over time and by region in which the incident has occurred?

- $\mathrm{H}_{2}$ : Does the price volatility response of distressed airline companies vary based on the scale of the disaster that they have experienced as measured by fatality and injury?

- $\mathrm{H}_{3}$ : Has the price volatility response of distressed airline companies changed over time?

- $\mathrm{H}_{4}$ : Does there exist a substantial change in dynamic correlation between the distressed company and broad aviation indices in the periods after such disaster?

- $H_{5}$ : Does there exist a substantial change in information flows between the distressed company and broad aviation indices in the periods after such disaster?

The above hypotheses thereby set out to analyse multiple facets of financial market distress in the aftermath of such tragedy. The results of this paper are of interest to the broad aviation sector, traders, regulators and policy-makers alike. While it is not surprising to observe that distressed aviation companies in such situations exhibit substantial and significant negative effects, it is very much of interest to further our understanding of the sources of such risk and indeed, as to whether it is contagious upon the entire aviation sector. Should there be evidence 
a) $1995-1999$

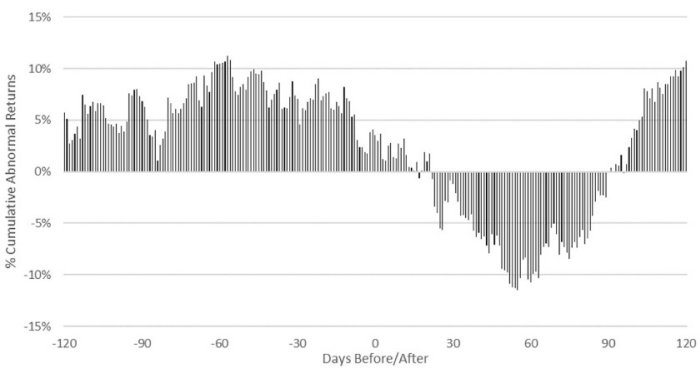

c) 2005-2009

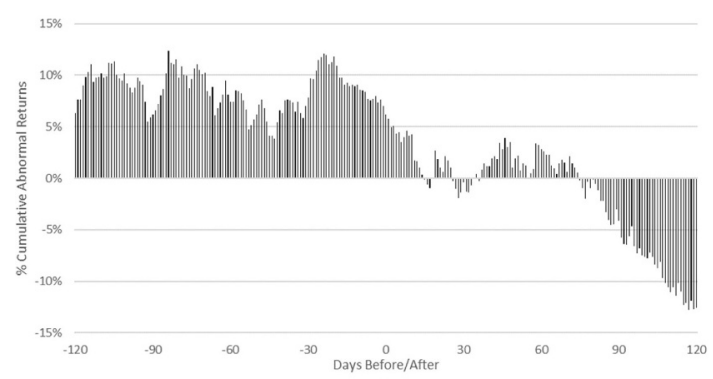

b) $2000-2004$

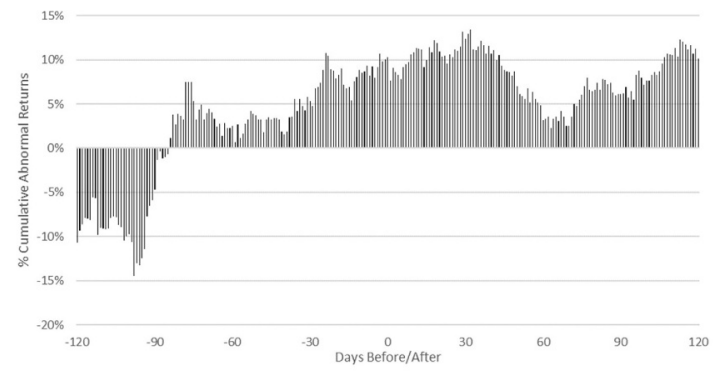

d) $2010-2014$

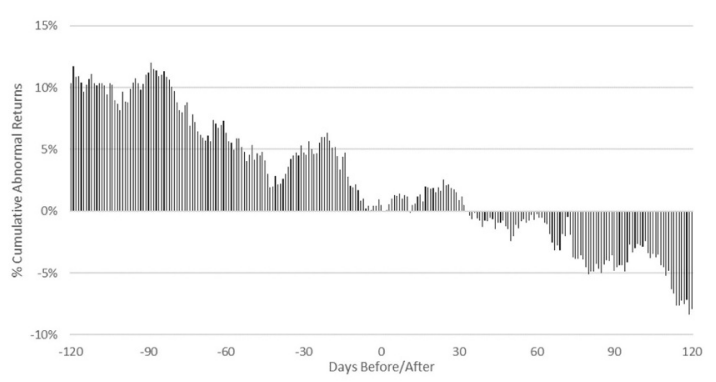

e) 2015-2019

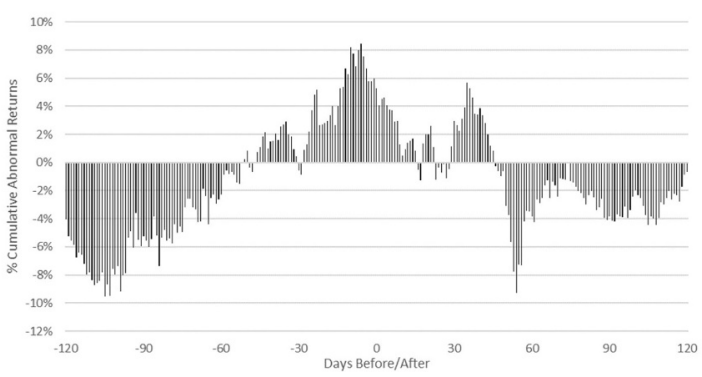

Fig. 5. Cumulative Abnormal Returns (CARs) over time due to airline disasters (1995-2019).

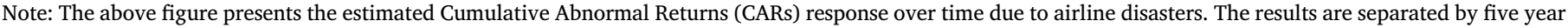
windows while presenting the average results for sixty days both before and after each incident for presentation purposes.

identified of a substantial link, this would develop potential fears about the broad financial safety of the sector and a strong potential for issues such as moral hazard and asymmetric information to develop as weaker, less regulatory compliant companies could potentially influence the growth, development and financial viability of companies who are behaving in a regulatory-compliant manner.

To begin our analysis, we first utilise a multivariate EGARCH(p,q) methodology to identify scale of the change in volatility in the period after the identified aviation incidents. At this stage, a number of goodness-of-fit testing procedures identified the EGARCH(1,1) model as the best selected to identify specific volatility changes in the companies' returns, thus we exercise our analysis using this model. ${ }^{2}$ The EGARCH specification developed on that of the GARCH specification proposed by Bollerslev (1986) and was designed to include lagged conditional variance terms as autoregressive terms. We specifically develop on an EGARCH methodology to analyse the volatility effects within the aviation industry due to aviation disasters. We first let $r_{t}=\left[r_{1}, t, \ldots, r_{n}\right.$,

\footnotetext{
${ }^{2}$ EGARCH exploits information contained in realised measures of volatility while providing a flexible leverage function that accounts for return-volatility dependence. While remaining in a GARCH-like modelling framework and estimation convenience, the model allows independent return and volatility shock and this dual shock nature leaves a room for the establishment of a variance risk premium.
}

$t^{\prime}$ be the vector of financial time series returns and $\varepsilon_{t}=\left[\varepsilon_{1}, t, \ldots, \varepsilon_{n, t}\right]^{\prime}$ be the vector of return residuals obtained after some filtration. Let $h_{i, t}$ be the corresponding conditional volatilities obtained from a univariate EGARCH process. We assume that $E_{t-1}\left[\varepsilon_{t}\right]=0$ and $E_{t-1}\left[\varepsilon_{t} \varepsilon_{t}^{\prime}\right]=H_{t}$, where $E_{t}[\cdot]$ is the conditional expectation on $\varepsilon_{t}, \varepsilon_{t-1}, \ldots$. Then the asset conditional covariance matrix $H_{t}$ can be written as

$H_{t}=D_{t}^{1 / 2} R_{t} D_{t}^{1 / 2}$

where $R_{t}=\left[\rho_{i j, t}\right]$ is the asset conditional correlation matrix and the diagonal matrix of the asset conditional variances is given by $D_{t}=\operatorname{diag}\left(h_{1}, t, \ldots, h_{n, t}\right)$. We express the variance equation of our EGARCH model as follows:

$\ln \left(h_{t}^{2}\right)=\omega+\alpha \varepsilon_{t-1}+\gamma\left(\left|\varepsilon_{t-1}\right|-E\left(\left|\varepsilon_{t-1}\right|\right)\right)+\beta \ln \left(h_{t-1}^{2}\right)+D_{t}$

which states that the value of the variance scaling parameter $h_{t}$ now depends both on the past value of the shocks, which are captured by the lagged square residual terms, and on past values of itself, which are captured by the lagged $h_{t}$ terms. Specification tests found that the EGARCH $(1,1)$ model served as the best fitting to estimate volatility effects through the use of dummy variables that are used to denote both the time-of-the-day and also periods of substantial traditional market volatility. ${ }^{3}$ It is also necessary to mitigate international effects which

\footnotetext{
${ }^{3}$ The optimal model is chosen according to three information criteria, namely
} 
a) Africa

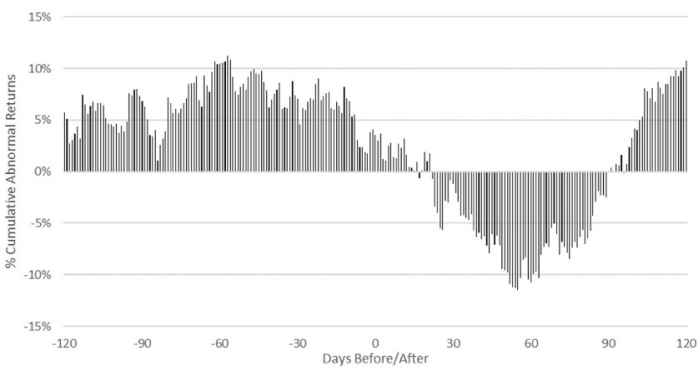

c) Europe

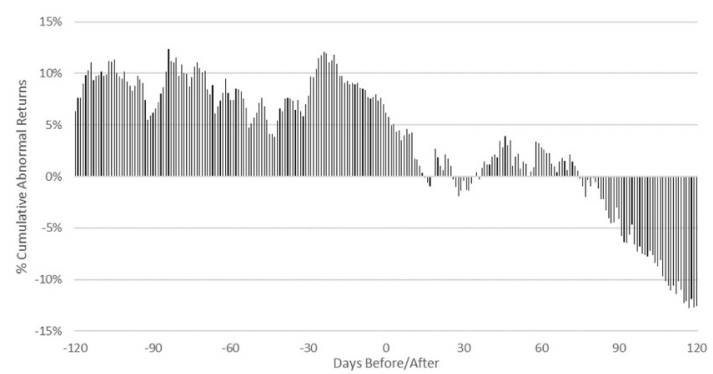

b) Asia

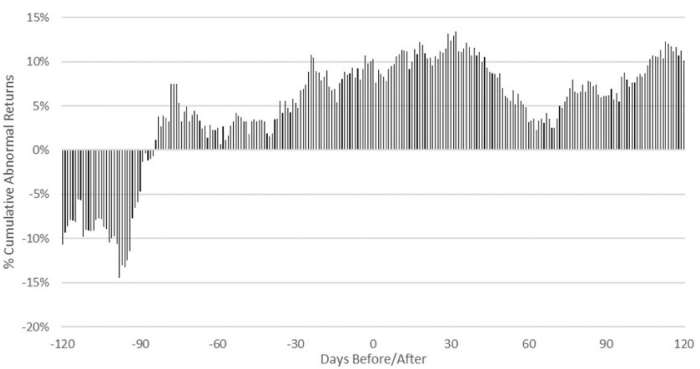

d) North America

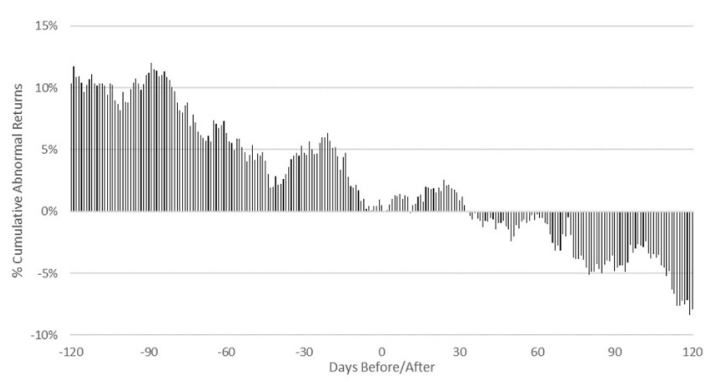

e) South America

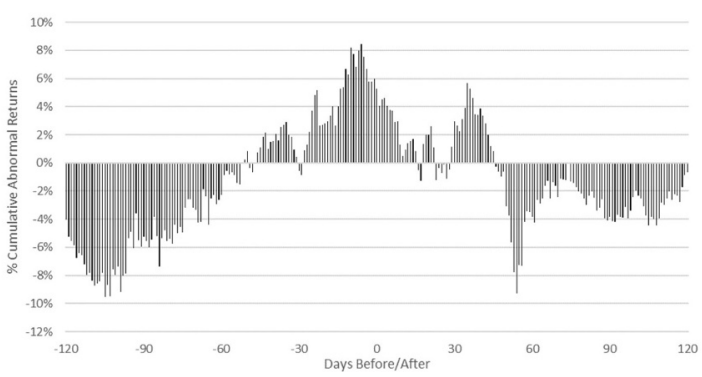

Fig. 6. Cumulative Abnormal Returns (CARs) by region due to airline disasters.

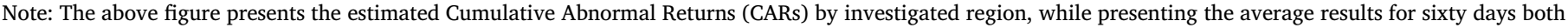
before and after each incident for presentation purposes.

can be completed through the inclusion of the returns of traditional financial products in the mean equation of the $\operatorname{EGARCH}(1,1)$ methodology. The volatility sourced in shocks that are incorporated in the returns of traditional financial markets are therefore considered in the volatility estimation of the selected structure. In summary, the estimated model has the following form:

$R_{t}=a_{0}+\sum_{j=1}^{5} b_{j} R_{t-n}+b_{2} D J I A_{t}+b_{3} W_{T} I_{t}+b_{4} A v E T F_{t}+\varepsilon_{t}$

$\ln \left(h_{t}^{2}\right)=\omega+\alpha \varepsilon_{t-1}+\gamma\left(\left|\varepsilon_{t-1}\right|-E\left(\left|\varepsilon_{t-1}\right|\right)\right)+\beta \ln \left(h_{t-1}^{2}\right)+D_{t}$

$R_{t-n}$ represents the lagged value of stock returns, $\mathrm{n}$ days before $R_{t}$ is observed. $D J I A_{t}$ represents the interaction between the distressed aviation company and the Dow Jones Industrial Average (DJIA), while

\section{(footnote continued)}

the Akaike (AIC), Bayesian (BIC) and Hannan-Quinn(HQ), all of which consider both how good the fitting of the model is and the number of parameters in the model, rewarding a better fitting and penalising an increased number of parameters for given data sets. The selected model is the one with the minimum criteria values. We also used a variety of dummy-lengths in Eq. (3), denoted as $D_{t}$ in the variance equation, but the twenty-day period after each selected event was denoted as the most stable specification across our selected methodologies. Results of all these specification tests are available from the authors on request.
$W T I_{t}$ represents the interaction with West Texas Intermediate oil prices (WTI), which is a market found to be very closely associated with the aviation sector (Kristjanpoller \& Concha, 2016; Yun \& Yoon, 2019), but also a very strong signal of multiple forms of economic strife (Chuang, Chiu, \& Edward Wang, 2008), therefore acting as a strong barometer of international effects within our selected methodological structure. Finally, $A \nu E T F_{t}$ represents that of the SPDR S\&P Transportation ETF (XTN) which is found to best represent the performance of aviation companies during the period analysed. Finally, $D_{t}$ is included in the variance equation to provide a coefficient relating to the volatility response to the thirty-day period after which the aviation tragedy has occurred.

In the next stage of our analysis, we investigate Hypothesis $H_{4}$, which specifically tests as to whether there has been a substantial change in dynamic correlations between the distressed company that has experienced the aviation disaster and the selected aviation indices in the period thereafter. To complete such an analysis, we test for the presence of such comovements in aviation markets and then specifically investigate their responses thereafter using a DCC-GARCH methodology. Engle (2002) models the right hand side of Eq. (1) rather than $H_{t}$ directly and proposes the dynamic correlation structure

$$
\begin{array}{r}
R_{t}=\left\{Q_{t}^{*}\right\}^{-1 / 2} Q_{t}\left\{Q_{t}^{*}\right\}^{-1 / 2}, \\
Q_{t}=(1-a-b) S+a u_{t-1} u_{t-1}^{\prime}+b Q_{t-1},
\end{array}
$$


Table 2

Significant increases in conditional volatility in the short-run after the event.

\begin{tabular}{|c|c|c|c|c|c|c|c|c|c|c|c|}
\hline Date & Event ID & $a_{0}$ & $R_{t-1}$ & $D J I A_{t}$ & $W T I_{t}$ & $A V I_{t}$ & $\omega$ & $\alpha$ & $\beta$ & $\gamma$ & $D_{t}$ \\
\hline 15/09/1995 & $\begin{array}{l}\text { Ev.2 } \\
\text { Std. Error }\end{array}$ & $\begin{array}{l}0.0004 \\
(0.0003)\end{array}$ & $\begin{array}{l}-0.0210 \\
(0.0140)\end{array}$ & $\begin{array}{l}0.0546^{* * *} \\
(0.0210)\end{array}$ & $\begin{array}{l}-0.0389 * * * \\
(0.0134)\end{array}$ & $\begin{array}{l}0.4510^{* * * *} \\
(0.0362)\end{array}$ & $\begin{array}{l}-0.0184 * k * \\
(0.0066)\end{array}$ & $\begin{array}{l}-0.0023 \\
(0.0075)\end{array}$ & $\begin{array}{l}0.9947 * * * \\
(0.0002)\end{array}$ & $\begin{array}{l}0.0755^{* * *} \\
(0.0044)\end{array}$ & $\begin{array}{l}0.0139 * * \\
(0.0065)\end{array}$ \\
\hline $15 / 08 / 1996$ & $\begin{array}{l}\text { Ev.4 } \\
\text { Std. Error }\end{array}$ & $\begin{array}{l}-0.0005^{* * *} \\
(0.0002)\end{array}$ & $\begin{array}{l}-0.0172 \\
(0.0142)\end{array}$ & $\begin{array}{l}0.0390 \\
(0.0289)\end{array}$ & $\begin{array}{l}-0.0241^{* * *} \\
(0.0072)\end{array}$ & $\begin{array}{l}0.8398 * * * \\
(0.0508)\end{array}$ & $\begin{array}{l}0.0199 * * * \\
(0.0022)\end{array}$ & $\begin{array}{l}-0.0020 \\
(0.0065)\end{array}$ & $\begin{array}{l}1.0000^{* * * *} \\
(0.0000)\end{array}$ & $\begin{array}{l}0.0339 * * * \\
(0.0001)\end{array}$ & $\begin{array}{l}0.0177^{* * *} \\
(0.0020)\end{array}$ \\
\hline 29/08/1996 & $\begin{array}{l}\text { Ev.5 } \\
\text { Std. Error }\end{array}$ & $\begin{array}{l}-0.0005^{* * *} \\
(0.0001)\end{array}$ & $\begin{array}{l}-0.0157^{*} \\
(0.0093)\end{array}$ & $\begin{array}{l}0.0388 * * * \\
(0.0138)\end{array}$ & $\begin{array}{l}-0.0233^{* * *} \\
(0.0083)\end{array}$ & $\begin{array}{l}0.8371 * * * \\
(0.0475)\end{array}$ & $\begin{array}{l}0.0199 * * * \\
(0.0022)\end{array}$ & $\begin{array}{l}-0.0023 \\
(0.0063)\end{array}$ & $\begin{array}{l}1.0000^{* * *} \\
(0.0000)\end{array}$ & $\begin{array}{l}0.0341^{* * *} \\
(0.0001)\end{array}$ & $\begin{array}{l}0.0177^{* * *} \\
(0.0020)\end{array}$ \\
\hline 06/08/1997 & $\begin{array}{l}\text { Ev.8 } \\
\text { Std. Error }\end{array}$ & $\begin{array}{l}-0.0005^{* * *} \\
(0.0002)\end{array}$ & $\begin{array}{l}-0.0049 * * * \\
(0.0006)\end{array}$ & $\begin{array}{l}0.0331 \\
(0.0413)\end{array}$ & $\begin{array}{l}-0.0180 \\
(0.0110)\end{array}$ & $\begin{array}{l}0.8036^{*} \\
(0.0509)\end{array}$ & $\begin{array}{l}-0.0080^{* *} \\
(0.0035)\end{array}$ & $\begin{array}{l}-0.0082 \\
(0.0077)\end{array}$ & $\begin{array}{l}0.9933^{* * * *} \\
(0.0000)\end{array}$ & $\begin{array}{l}0.0677^{* * *} \\
(0.0005)\end{array}$ & $\begin{array}{l}0.0393^{* * *} \\
(0.0037)\end{array}$ \\
\hline $15 / 10 / 1997$ & $\begin{array}{l}\text { Ev.9 } \\
\text { Std. Error }\end{array}$ & $\begin{array}{l}0.0001 \\
(0.0004)\end{array}$ & $\begin{array}{l}0.1546 * * * \\
(0.0163)\end{array}$ & $\begin{array}{l}0.1523^{* *} \\
(0.0766)\end{array}$ & $\begin{array}{l}-0.0063 \\
(0.0130)\end{array}$ & $\begin{array}{l}0.3184^{* * * *} \\
(0.0490)\end{array}$ & $\begin{array}{l}-0.0770 * * \\
(0.0174)\end{array}$ & $\begin{array}{l}-0.0289^{* * *} \\
(0.0124)\end{array}$ & $\begin{array}{l}0.9834^{* * * *} \\
(0.0016)\end{array}$ & $\begin{array}{l}0.1407 * * \\
(0.0152)\end{array}$ & $\begin{array}{l}0.0455^{* * *} \\
(0.0103)\end{array}$ \\
\hline $14 / 08 / 1998$ & $\begin{array}{l}\text { Ev.12 } \\
\text { Std. Error }\end{array}$ & $\begin{array}{l}-0.0004^{* *} \\
(0.0002)\end{array}$ & $\begin{array}{l}-0.0074 \\
(0.0054)\end{array}$ & $\begin{array}{l}0.0226 * * \\
(0.0114)\end{array}$ & $\begin{array}{l}-0.0188 \\
(0.0118)\end{array}$ & $\begin{array}{l}0.8157^{* * *} \\
(0.0388)\end{array}$ & $\begin{array}{l}-0.0515^{* * *} \\
(0.0023)\end{array}$ & $\begin{array}{l}-0.0046 \\
(0.0097)\end{array}$ & $\begin{array}{l}0.9857 * * * * \\
(0.0003)\end{array}$ & $\begin{array}{l}0.0818^{* * *} \\
(0.0092)\end{array}$ & $\begin{array}{l}0.0534 * * * \\
(0.0029)\end{array}$ \\
\hline $31 / 01 / 2000$ & $\begin{array}{l}\text { Ev.14 } \\
\text { Std. Error }\end{array}$ & $\begin{array}{l}0.0000 \\
(0.0006)\end{array}$ & $\begin{array}{l}0.0267 \\
(0.0235)\end{array}$ & $\begin{array}{l}-0.1103 \\
(0.0840)\end{array}$ & $\begin{array}{l}0.0903^{* * *} \\
(0.0177)\end{array}$ & $\begin{array}{l}0.3918^{* * * *} \\
(0.0833)\end{array}$ & $\begin{array}{l}0.0612 * * * \\
(0.0123)\end{array}$ & $\begin{array}{l}-0.0131 \\
(0.0171)\end{array}$ & $\begin{array}{l}0.9563^{* * *} \\
(0.0009)\end{array}$ & $\begin{array}{l}0.1970 * * * \\
(0.0412)\end{array}$ & $\begin{array}{l}0.3716 * * * \\
(0.0071)\end{array}$ \\
\hline $06 / 03 / 2000$ & $\begin{array}{l}\text { Ev.15 } \\
\text { Std. Error }\end{array}$ & $\begin{array}{l}-0.0015^{* *} \\
(0.0007)\end{array}$ & $\begin{array}{l}-0.0506^{* * *} \\
(0.0119)\end{array}$ & $\begin{array}{l}-0.0359 * * * \\
(0.0026)\end{array}$ & $\begin{array}{l}0.1184 * \\
(0.0633)\end{array}$ & $\begin{array}{l}0.0111^{* * *} \\
(0.0014)\end{array}$ & $\begin{array}{l}-0.5107^{* *} \\
(0.2304)\end{array}$ & $\begin{array}{l}-0.0069 \\
(0.0151)\end{array}$ & $\begin{array}{l}0.9149 * * * \\
(0.0367)\end{array}$ & $\begin{array}{l}0.2388 * \\
(0.0520)\end{array}$ & $\begin{array}{l}0.0345^{* *} \\
(0.0171)\end{array}$ \\
\hline $24 / 04 / 2000$ & $\begin{array}{l}\text { Ev.16 } \\
\text { Std. Error }\end{array}$ & $\begin{array}{l}0.0000 \\
(0.0002)\end{array}$ & $\begin{array}{l}0.0338 \\
(0.0205)\end{array}$ & $\begin{array}{l}-0.1087^{* *} \\
(0.0481)\end{array}$ & $\begin{array}{l}0.0916^{* * *} \\
(0.0141)\end{array}$ & $\begin{array}{l}0.3875^{* * *} \\
(0.0507)\end{array}$ & $\begin{array}{l}0.0332^{* * *} \\
(0.0081)\end{array}$ & $\begin{array}{l}-0.0149 \\
(0.0176)\end{array}$ & $\begin{array}{l}0.9446 * * * \\
(0.0050)\end{array}$ & $\begin{array}{l}0.2136^{*} \\
(0.0695)\end{array}$ & $\begin{array}{l}0.4324 * * * \\
(0.0293)\end{array}$ \\
\hline $01 / 05 / 2000$ & $\begin{array}{l}\text { Ev.17 } \\
\text { Std. Error }\end{array}$ & $\begin{array}{l}0.0000 \\
(0.0002)\end{array}$ & $\begin{array}{l}0.0338 \\
(0.0262)\end{array}$ & $\begin{array}{l}-0.1072^{*} \\
(0.0603)\end{array}$ & $\begin{array}{l}0.0914^{* * *} \\
(0.0137)\end{array}$ & $\begin{array}{l}0.3864^{* * *} \\
(0.0629)\end{array}$ & $\begin{array}{l}0.0318 \\
(0.0734)\end{array}$ & $\begin{array}{l}-0.0145 \\
(0.0174)\end{array}$ & $\begin{array}{l}0.9447 * * * \\
(0.0157)\end{array}$ & $\begin{array}{l}0.2132 \\
(0.1067)\end{array}$ & $\begin{array}{l}0.4309 * * * \\
(0.1521)\end{array}$ \\
\hline $31 / 10 / 2000$ & $\begin{array}{l}\text { Ev. } 20 \\
\text { Std. Error }\end{array}$ & $\begin{array}{l}-0.0004^{* * *} \\
(0.0001)\end{array}$ & $\begin{array}{l}-0.1104^{* * *} \\
(0.0135)\end{array}$ & $\begin{array}{l}-0.0087 * * \\
(0.0044)\end{array}$ & $\begin{array}{l}0.0035^{* *} \\
(0.0014)\end{array}$ & $\begin{array}{l}0.2292^{* * *} \\
(0.0207)\end{array}$ & $\begin{array}{l}-0.1828^{* * *} \\
(0.0097)\end{array}$ & $\begin{array}{l}-0.0144^{* * *} \\
(0.0051)\end{array}$ & $\begin{array}{l}0.9748^{* * *} \\
(0.0008)\end{array}$ & $\begin{array}{l}0.2356^{* *} \\
(0.0302)\end{array}$ & $\begin{array}{l}0.0196 * * \\
(0.0084)\end{array}$ \\
\hline $27 / 08 / 2001$ & $\begin{array}{l}\text { Ev.21 } \\
\text { Std. Error }\end{array}$ & $\begin{array}{l}0.0001 \\
(0.0006)\end{array}$ & $\begin{array}{l}0.0344 \\
(0.0295)\end{array}$ & $\begin{array}{l}-0.0888 \\
(0.0667)\end{array}$ & $\begin{array}{l}0.0829 * * * \\
(0.0163)\end{array}$ & $\begin{array}{l}0.3629^{* * * *} \\
(0.0778)\end{array}$ & $\begin{array}{l}-1.0888^{* *} \\
(0.4961)\end{array}$ & $\begin{array}{l}0.0174 \\
(0.0428)\end{array}$ & $\begin{array}{l}0.7773 * * * \\
(0.0982)\end{array}$ & $\begin{array}{l}0.2606 \\
(0.0840)\end{array}$ & $\begin{array}{l}0.6206 * * \\
(0.3131)\end{array}$ \\
\hline 08/01/2003 & $\begin{array}{l}\text { Ev.26 } \\
\text { Std. Error }\end{array}$ & $\begin{array}{l}0.0001 \\
(0.0002)\end{array}$ & $\begin{array}{l}-0.0236 \\
(0.0147)\end{array}$ & $\begin{array}{l}0.0219 \\
(0.0160)\end{array}$ & $\begin{array}{l}-0.0239 \\
(0.0154)\end{array}$ & $\begin{array}{l}0.4379 * * * \\
(0.0382)\end{array}$ & $\begin{array}{l}-0.5586^{* * *} \\
(0.0186)\end{array}$ & $\begin{array}{l}-0.0029 \\
(0.0123)\end{array}$ & $\begin{array}{l}0.9079 * * * \\
(0.0030)\end{array}$ & $\begin{array}{l}0.1412^{* * *} \\
(0.0309)\end{array}$ & $\begin{array}{l}0.1204 * * * \\
(0.0102)\end{array}$ \\
\hline $06 / 03 / 2003$ & $\begin{array}{l}\text { Ev.27 } \\
\text { Std. Error }\end{array}$ & $\begin{array}{l}-0.0010^{* * *} \\
(0.0003)\end{array}$ & $\begin{array}{l}-0.0646^{* * *} \\
(0.0130)\end{array}$ & $\begin{array}{l}-0.0692 \\
(0.0546)\end{array}$ & $\begin{array}{l}-0.1057 \\
(0.0757)\end{array}$ & $\begin{array}{l}0.1384 * * * \\
(0.0535)\end{array}$ & $\begin{array}{l}-0.5979 * * \\
(0.2858)\end{array}$ & $\begin{array}{l}-0.0089 \\
(0.0156)\end{array}$ & $\begin{array}{l}0.9027^{* * *} \\
(0.0452)\end{array}$ & $\begin{array}{l}0.2400 * * * \\
(0.0627)\end{array}$ & $\begin{array}{l}0.0310^{*} \\
(0.0166)\end{array}$ \\
\hline 03/02/2005 & $\begin{array}{l}\text { Ev.29 } \\
\text { Std. Error }\end{array}$ & $\begin{array}{l}-0.0004^{* * *} \\
(0.0001)\end{array}$ & $\begin{array}{l}-0.1155 \\
(0.1469)\end{array}$ & $\begin{array}{l}0.0084 \\
(0.2261)\end{array}$ & $\begin{array}{l}0.0053 \\
(0.0218)\end{array}$ & $\begin{array}{l}0.2155^{* *} \\
(0.1001)\end{array}$ & $\begin{array}{l}-0.2463^{* * *} \\
(0.0459)\end{array}$ & $\begin{array}{l}-0.0142 \\
(0.0151)\end{array}$ & $\begin{array}{l}0.9672 * * * \\
(0.0059)\end{array}$ & $\begin{array}{l}0.2468^{* * * *} \\
(0.0365)\end{array}$ & $\begin{array}{l}0.0262^{* * *} \\
(0.0081)\end{array}$ \\
\hline $21 / 06 / 2006$ & $\begin{array}{l}\text { Ev.30 } \\
\text { Std. Error }\end{array}$ & $\begin{array}{l}0.0003 \\
(0.0004)\end{array}$ & $\begin{array}{l}-0.0230 \\
(0.0158)\end{array}$ & $\begin{array}{l}0.0283 \\
(0.0741)\end{array}$ & $\begin{array}{l}-0.0286 \\
(0.0214)\end{array}$ & $\begin{array}{l}0.4348 * * * \\
(0.0807)\end{array}$ & $\begin{array}{l}-0.2536^{* * *} \\
(0.0231)\end{array}$ & $\begin{array}{l}-0.0032 \\
(0.0106)\end{array}$ & $\begin{array}{l}0.9588^{* * * *} \\
(0.0042)\end{array}$ & $\begin{array}{l}0.1487 * * * \\
(0.0276)\end{array}$ & $\begin{array}{l}0.0495^{* * *} \\
(0.0096)\end{array}$ \\
\hline $07 / 05 / 2007$ & $\begin{array}{l}\text { Ev.35 } \\
\text { Std. Error }\end{array}$ & $\begin{array}{l}0.0000 \\
(0.0002)\end{array}$ & $\begin{array}{l}0.3739 \\
(1.8072)\end{array}$ & $\begin{array}{l}0.0000 \\
(0.0006)\end{array}$ & $\begin{array}{l}0.0000 \\
(0.0006)\end{array}$ & $\begin{array}{l}0.0000 \\
(0.0006)\end{array}$ & $\begin{array}{l}-0.1386 \\
(0.5712)\end{array}$ & $\begin{array}{l}0.1839 \\
(1.7155)\end{array}$ & $\begin{array}{l}0.9896^{* * * *} \\
(0.1000)\end{array}$ & $\begin{array}{l}0.5064 \\
(0.6920)\end{array}$ & $\begin{array}{l}0.1835^{*} \\
(0.1034)\end{array}$ \\
\hline $17 / 07 / 2007$ & $\begin{array}{l}\text { Ev.36 } \\
\text { Std. Error }\end{array}$ & $\begin{array}{l}0.0002^{* *} \\
(0.0001)\end{array}$ & $\begin{array}{l}0.1556 * * * \\
(0.0150)\end{array}$ & $\begin{array}{l}0.1673^{* * *} \\
(0.0400)\end{array}$ & $\begin{array}{l}-0.0098^{* * *} \\
(0.0016)\end{array}$ & $\begin{array}{l}0.3090 * * * \\
(0.0361)\end{array}$ & $\begin{array}{l}-0.2578^{* * *} \\
(0.0145)\end{array}$ & $\begin{array}{l}-0.0323^{* *} \\
(0.0147)\end{array}$ & $\begin{array}{l}0.9632^{* * *} \\
(0.0015)\end{array}$ & $\begin{array}{l}0.1690^{* * *} \\
(0.0134)\end{array}$ & $\begin{array}{l}0.0439 * * * \\
(0.0074)\end{array}$ \\
\hline $13 / 08 / 2007$ & $\begin{array}{l}\text { Ev.37 } \\
\text { Std. Error }\end{array}$ & $\begin{array}{l}-0.0001 * * * \\
(0.0007)\end{array}$ & $\begin{array}{l}0.0694 * * \\
(0.0320)\end{array}$ & $\begin{array}{l}0.3947 \\
(0.2561)\end{array}$ & $\begin{array}{l}-0.1005^{* *} \\
(0.0306)\end{array}$ & $\begin{array}{l}0.5097 \\
(0.2571)\end{array}$ & $\begin{array}{l}-0.0386^{* * *} \\
(0.0066)\end{array}$ & $\begin{array}{l}-0.0245^{* *} \\
(0.0107)\end{array}$ & $\begin{array}{l}0.9958^{* * *} \\
(0.0004)\end{array}$ & $\begin{array}{l}0.1007^{* * *} \\
(0.0062)\end{array}$ & $\begin{array}{l}0.0209 * * * \\
(0.0063)\end{array}$ \\
\hline $14 / 09 / 2007$ & $\begin{array}{l}\text { Ev.39 } \\
\text { Std. Error }\end{array}$ & $\begin{array}{l}0.0003^{* * *} \\
(0.0002)\end{array}$ & $\begin{array}{l}-0.0237^{* * *} \\
(0.0073)\end{array}$ & $\begin{array}{l}0.0340 * * \\
(0.0280)\end{array}$ & $\begin{array}{l}-0.0328^{* *} \\
(0.0119)\end{array}$ & $\begin{array}{l}0.4396 * * \\
(0.0461)\end{array}$ & $\begin{array}{l}-0.1221^{* *} \\
(0.0197)\end{array}$ & $\begin{array}{l}-0.0044 \\
(0.0087)\end{array}$ & $\begin{array}{l}0.9799 * * * \\
(0.0034)\end{array}$ & $\begin{array}{l}0.1139 * * * \\
(0.0197)\end{array}$ & $\begin{array}{l}0.0229^{* * *} \\
(0.0054)\end{array}$ \\
\hline $15 / 09 / 2008$ & $\begin{array}{l}\text { Ev. } 41 \\
\text { Std. Error }\end{array}$ & $\begin{array}{l}0.0003 \\
(0.0007)\end{array}$ & $\begin{array}{l}-0.0245^{* *} \\
(0.0117)\end{array}$ & $\begin{array}{l}0.0546 \\
(0.0634)\end{array}$ & $\begin{array}{l}-0.0338 \\
(0.0256)\end{array}$ & $\begin{array}{l}0.4338 * * * \\
(0.1460)\end{array}$ & $\begin{array}{l}-0.1059 * * * \\
(0.0335)\end{array}$ & $\begin{array}{l}-0.0015 \\
(0.0103)\end{array}$ & $\begin{array}{l}0.9826^{* * *} \\
(0.0048)\end{array}$ & $\begin{array}{l}0.1050 * * * \\
(0.0237)\end{array}$ & $\begin{array}{l}0.0203^{* * *} \\
(0.0034)\end{array}$ \\
\hline $12 / 01 / 2009$ & $\begin{array}{l}\text { Ev. } 43 \\
\text { Std. Error }\end{array}$ & $\begin{array}{l}-0.0001 \\
(0.0003)\end{array}$ & $\begin{array}{l}0.0022 \\
(0.0173)\end{array}$ & $\begin{array}{l}1.1424 * * * \\
(0.0783)\end{array}$ & $\begin{array}{l}-0.2101^{* * *} \\
(0.0228)\end{array}$ & $\begin{array}{l}0.2868^{* * *} \\
(0.0868)\end{array}$ & $\begin{array}{l}-0.0127^{* * *} \\
(0.0021)\end{array}$ & $\begin{array}{l}-0.0136 \\
(0.0083)\end{array}$ & $\begin{array}{l}0.9970 * * * \\
(0.0000)\end{array}$ & $\begin{array}{l}0.0360 * * * \\
(0.0003)\end{array}$ & $\begin{array}{l}0.0102 * * * \\
(0.0022)\end{array}$ \\
\hline $29 / 11 / 2013$ & $\begin{array}{l}\text { Ev. } 56 \\
\text { Std. Error }\end{array}$ & $\begin{array}{l}0.0000 \\
(0.0001)\end{array}$ & $\begin{array}{l}0.0891 \\
(0.2865)\end{array}$ & $\begin{array}{l}0.0000 \\
(0.0003)\end{array}$ & $\begin{array}{l}0.0000 \\
(0.0003)\end{array}$ & $\begin{array}{l}0.0000 \\
(0.0003)\end{array}$ & $\begin{array}{l}-0.0109 \\
(1.0367)\end{array}$ & $\begin{array}{l}-0.1072 \\
(2.2909)\end{array}$ & $\begin{array}{l}0.9872^{* * *} \\
(0.0021)\end{array}$ & $\begin{array}{l}0.9912 \\
(1.7238)\end{array}$ & $\begin{array}{l}0.2575^{*} \\
(0.1530)\end{array}$ \\
\hline 04/03/2019 & $\begin{array}{l}\text { Ev.67 } \\
\text { Std. Error }\end{array}$ & $\begin{array}{l}-0.0017^{* * *} \\
(0.0002)\end{array}$ & $\begin{array}{l}-0.0537^{* * *} \\
(0.0125)\end{array}$ & $\begin{array}{l}-0.0246 \\
(0.0513)\end{array}$ & $\begin{array}{l}0.1157^{*} \\
(0.0653)\end{array}$ & $\begin{array}{l}-0.0074 \\
(0.0442)\end{array}$ & $\begin{array}{l}-0.5349^{* * *} \\
(0.2561)\end{array}$ & $\begin{array}{l}-0.0011 \\
(0.0142)\end{array}$ & $\begin{array}{l}0.9155^{* * *} \\
(0.0397)\end{array}$ & $\begin{array}{l}0.2342^{* * *} \\
(0.0546)\end{array}$ & $\begin{array}{l}0.0963^{*} \\
(0.0516)\end{array}$ \\
\hline
\end{tabular}

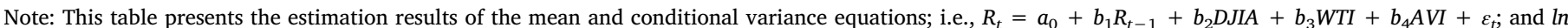

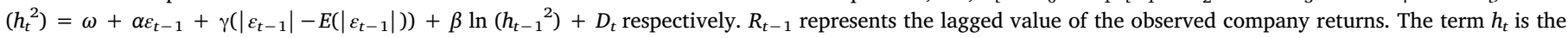

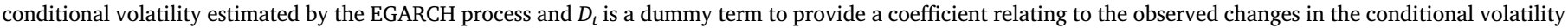

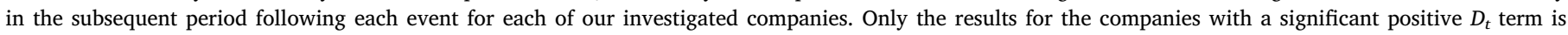

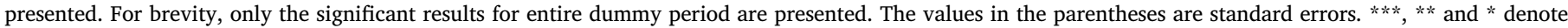
significant at the $1 \%, 5 \%$ and $10 \%$ level respectively.

where $Q_{t} \equiv\left[q_{i j, t}\right], u_{t}=\left[u_{1, t}, \ldots, u_{n, t}\right]^{\prime}$ and $u_{i, t}$ is the transformed residuals i.e. $u_{i, t}=\varepsilon_{i, t} / h_{i, t}, S \equiv\left[s_{i j}\right]=E\left[u_{t} u_{t}^{\prime}\right]$ is the $n \times n$ unconditional covariance matrix of $u_{t}, Q_{t}^{*}=\operatorname{diag}\left\{Q_{t}\right\}$ and $a, b$ are nonnegative scalars satisfying $a+b<1$. The parameters of the DCC model are estimated by using the quasi-maximum likelihood method with respect to the log-likelihood function, and according to the state twostep procedure. When specifying the form of the conditional correlation matrix $R_{t}$, two requirements have to be considered. The first is that the covariance matrix $H_{t}$ has to be positive and the second is that all the elements in the conditional correlation matrix $R_{t}$ have to be equal or less than unity. The DCC model is estimated by using a two-step approach to maximise the log-likelihood function. As proposed by Engle (2002), the DCC-GARCH model is designed to allow for a two-stage estimation of the conditional variance matrix $h_{t}$. In the first stage, univariate GARCH $(1,1)$ volatility models are fitted for each of the stock return residuals and estimates of $\sqrt{h_{i t}}$ are obtained. In the second stage, stock return residuals are transformed by their estimated standard deviations from the first stage as $z_{i t}=\frac{\epsilon_{i t}}{\sqrt{h_{i t}}}$. Finally, the standardised residual $z_{i t}$ is used to estimate the correlation parameters. If we let $\theta$ denote the parameters in $D_{t}$ and $\vartheta$, the parameters in $R_{t}$, then the loglikelihood is:

$$
\begin{aligned}
l_{t}(\theta, \vartheta) \\
=\left[-\frac{1}{2} \sum_{t=1}^{T} n \log (2 \pi)+\log \left|D_{t}\right|^{2}+\varepsilon_{t}^{\prime} D_{t}^{-2} \varepsilon t\right]+\left[\Sigma_{t=1}^{T} \log \left|R_{t}\right| z_{t}^{\prime} R_{t}^{-1}\right. \\
\left.\quad z_{t}-z_{t}^{\prime} z_{t}\right]
\end{aligned}
$$

The first part of the log likelihood function is volatility, which is the sum of the individual GARCH likelihoods. The log-likelihood function 
Table 3

Number(percent) of companies experiencing an increase in their stock returns' unconditional volatility in the short and long-run after the (crash) event.

\begin{tabular}{|c|c|c|c|c|c|}
\hline Company & {$[-10,+10]$} & {$[-20,+20]$} & {$[-40,+40]$} & {$[-60,+60]$} & $\begin{array}{l}\text { [all pre- } \\
\text { ann, all } \\
\text { post-ann] }\end{array}$ \\
\hline \multicolumn{6}{|c|}{ Panel A: Log-returns with higher variance } \\
\hline 2610.TW & $3(100)$ & $3(100)$ & $1(33.33)$ & $1(33.33)$ & $1(33.33)$ \\
\hline AC.TO & $1(100)$ & $1(100)$ & $1(100)$ & $1(100)$ & $1(100)$ \\
\hline AEROMEX & $1(50)$ & $1(50)$ & $2(100)$ & $2(100)$ & $1(50)$ \\
\hline AFLT & $2(50)$ & $1(25)$ & $1(25)$ & $1(25)$ & $0(0)$ \\
\hline AIRA.KL & $0(0)$ & $0(0)$ & $1(100)$ & $1(100)$ & $1(100)$ \\
\hline AIRF.PA & $4(80)$ & $3(60)$ & $2(40)$ & $1(20)$ & $0(0)$ \\
\hline ALK & $1(100)$ & $1(100)$ & $1(100)$ & $1(100)$ & $0(0)$ \\
\hline $\mathrm{BA}$ & $3(75)$ & $2(50)$ & $0(0)$ & $0(0)$ & $2(50)$ \\
\hline DAL & $1(50)$ & $2(100)$ & $2(100)$ & $2(100)$ & $0(0)$ \\
\hline GIAA.JK & 1 (100) & $0(0)$ & 1 (100) & $1(100)$ & 1 (100) \\
\hline LTM.SN & $3(75)$ & $3(75)$ & $2(50)$ & $2(50)$ & $1(25)$ \\
\hline MASM & $3(100)$ & $2(66.67)$ & $2(66.67)$ & $2(66.67)$ & $1(33.33)$ \\
\hline PIAa.KA & $3(50)$ & $3(50)$ & $2(33.33)$ & $3(50)$ & $2(33.33)$ \\
\hline THYAO.IS & $3(50)$ & $2(33.33)$ & $2(33.33)$ & $2(33.33)$ & $0(0)$ \\
\hline UAL.O & $4(100)$ & $4(100)$ & $3(75)$ & $3(75)$ & $0(0)$ \\
\hline UTAR.MM & 1 (33.33) & 1 (33.33) & $2(66.67)$ & $2(66.67)$ & $0(0)$ \\
\hline ALL & $39(58.21)$ & $35(52.24)$ & 31 (46.27) & $30(44.78)$ & $13(19.4)$ \\
\hline \multicolumn{6}{|c|}{ Panel B: Log-returns with significantly higher variance } \\
\hline AEROMEX & $1(50)$ & $1(50)$ & $2(100)$ & $2(100)$ & $0(0)$ \\
\hline AFLT & $2(50)$ & $1(25)$ & $1(25)$ & $1(25)$ & $0(0)$ \\
\hline AIRF.PA & $3(60)$ & $2(40)$ & $1(20)$ & $0(0)$ & $0(0)$ \\
\hline DAL & $0(0)$ & $1(50)$ & $2(100)$ & $1(50)$ & $0(0)$ \\
\hline LTM.SN & $1(25)$ & $2(50)$ & $2(50)$ & $2(50)$ & $1(25)$ \\
\hline MASM & $2(66.67)$ & $1(33.33)$ & $1(33.33)$ & $2(66.67)$ & $1(33.33)$ \\
\hline PIAa.KA & $0(0)$ & $1(16.67)$ & $0(0)$ & $2(33.33)$ & $2(33.33)$ \\
\hline THYAO.IS & $2(33.33)$ & $2(33.33)$ & $2(33.33)$ & $2(33.33)$ & $0(0)$ \\
\hline UAL.O & $2(50)$ & $2(50)$ & $2(50)$ & $3(75)$ & $0(0)$ \\
\hline ALL & $17(25.37)$ & $17(25.37)$ & $18(26.87)$ & $20(29.85)$ & $11(16.42)$ \\
\hline \multicolumn{6}{|c|}{ Panel C: Excess log-returns with higher variance } \\
\hline 2610.TW & $3(100)$ & $3(100)$ & $3(100)$ & $3(100)$ & $1(33.33)$ \\
\hline AEROMEX & $1(50)$ & $1(50)$ & $2(100)$ & $2(100)$ & $2(100)$ \\
\hline AFLT & $3(75)$ & $2(50)$ & $1(25)$ & $1(25)$ & $0(0)$ \\
\hline AIRF.PA & $4(80)$ & $3(60)$ & $2(40)$ & $1(20)$ & $0(0)$ \\
\hline $\mathrm{BA}$ & $3(75)$ & $2(50)$ & $1(25)$ & $1(25)$ & $2(50)$ \\
\hline DAL & $1(50)$ & $2(100)$ & $2(100)$ & $2(100)$ & $0(0)$ \\
\hline LTM.SN & $2(50)$ & $3(75)$ & $3(75)$ & $2(50)$ & $1(25)$ \\
\hline MASM & $3(100)$ & $3(100)$ & $2(66.67)$ & $2(66.67)$ & $1(33.33)$ \\
\hline PIAa.KA & $2(33.33)$ & $2(33.33)$ & $3(50)$ & $3(50)$ & $2(33.33)$ \\
\hline THYAO.IS & $4(66.67)$ & $2(33.33)$ & $2(33.33)$ & $2(33.33)$ & $0(0)$ \\
\hline UAL.O & $4(100)$ & $4(100)$ & $4(100)$ & $4(100)$ & $0(0)$ \\
\hline UTAR.MM & $2(66.67)$ & $1(33.33)$ & $2(66.67)$ & $1(33.33)$ & $0(0)$ \\
\hline ALL & $40(25.37)$ & $36(28.36)$ & 35 (25.37) & $31(23.88)$ & $13(16.42)$ \\
\hline \multicolumn{6}{|c|}{ Panel D: Excess log-returns with significantly higher variance } \\
\hline AFLT & $2(50)$ & $1(25)$ & $1(25)$ & $1(25)$ & $0(0)$ \\
\hline DAL & $1(50)$ & $1(50)$ & $2(100)$ & $0(0)$ & $0(0)$ \\
\hline LTM.SN & $1(25)$ & $3(75)$ & $2(50)$ & $1(25)$ & $1(25)$ \\
\hline MASM & $2(66.67)$ & $1(33.33)$ & $1(33.33)$ & $2(66.67)$ & $1(33.33)$ \\
\hline PIAa.KA & $1(16.67)$ & $2(33.33)$ & $0(0)$ & $2(33.33)$ & $2(33.33)$ \\
\hline THYAO.IS & $1(16.67)$ & $2(33.33)$ & $2(33.33)$ & $2(33.33)$ & $0(0)$ \\
\hline UAL.O & $2(50)$ & $3(75)$ & $2(50)$ & $2(50)$ & $0(0)$ \\
\hline ALL & $17(25.37)$ & $19(28.36)$ & 17 (25.37) & $16(23.88)$ & $11(16.42)$ \\
\hline
\end{tabular}

Note: This table shows the number of companies that experience a higher unconditional volatility in their stock prices after announcements. The column headers show the unconditional volatility calculation periods in days before and after the announcements. In the table, the values in the parentheses are the percentage of companies within the sub-groups experiencing an increase in their stock returns' unconditional variances. Panel A (Panel B) reports the number of companies that experience a (significantly) higher variance in their stocks' daily returns. Panel C (Panel D) reports the number of companies that experience a (significantly) higher variance in their stocks' daily excess returns over the corresponding market returns. For brevity, only significant and results above zero are presented.

can be maximised in the first stage over the parameters $D_{t}$. Given the estimated parameters in the first stage, the correlation component of the likelihood function in the second stage is maximised to estimate the correlation coefficients. Finally, we examine the DCC-GARCH model's change in behaviour before and after each airline disaster, measuring the specific relationship between the associated airline and the broad aviation sector as measured by the SPDR S\&P Transportation ETF (XTN).

In the final stage of our analysis, and to provide additional methodological robustness, we analyse the changing behaviour of price discovery in the periods after such aviation disasters. There are two standard measures of price discovery commonly employed in the literature: the Hasbrouck (1995) Information Share (IS) and the Gonzalo and Granger (1995) Component Share (CS) approach. Hasbrouck (1995) demonstrates that the contribution of a price series to price discovery (the 'Information Share') can be measured by the proportion of the variance in the common efficient price innovations that is explained by innovations in that price series. Gonzalo and Granger (1995) decompose a cointegrated price series into a permanent component and a temporary component using error correction coefficients. The permanent component is interpreted as the common efficient price, the temporary component reflects deviations from the efficient price caused by trading fractions. We estimate IS and CS, as developed by Hauptfleisch, Putniņš, and Lucey (2016) using the error correction parameters and variance-covariance of the error terms from the Vector Error Correction Model (VECM):

$\Delta_{p 1, t}=\alpha_{1}\left(p_{1, t-1}-p_{2, t-1}\right)+\sum_{i=1}^{200} \gamma_{i} \Delta p_{1, t-i}+\sum_{j=1}^{200} \delta_{j} \Delta p_{2, t-j}+\varepsilon_{1, t}$

$\Delta_{p 2, t}=\alpha_{2}\left(p_{1, t-1}-p_{2, t-1}\right)+\sum_{k=1}^{200} \varphi_{k} \Delta p_{1, t-k}+\sum_{m=1}^{200} \phi_{m} \Delta p_{2, t-m}+\varepsilon_{2, t}$

where $\Delta p_{i, t}$ is the change in the log price $\left(p_{i, t}\right)$ of the asset traded in market $i$ at time $t$. The next stage is to obtain the component shares from the normalised orthogonal vector of error correction coefficients, therefore:

$C S_{1}=\gamma_{1}=\frac{\alpha_{2}}{\alpha_{2}-\alpha_{1}} ; C S_{2}=\gamma_{2}=\frac{\alpha_{1}}{\alpha_{1}-\alpha_{2}}$

Given the covariance matrix of the reduced form VECM error terms ${ }^{4}$ where:

$M=\left(\begin{array}{cc}m_{11} & 0 \\ m_{12} & m_{22}\end{array}\right)=\left(\begin{array}{cc}\sigma_{1} & 0 \\ \rho \sigma_{2} & \sigma_{2}\left(1-\rho^{2}\right)^{\frac{1}{2}}\end{array}\right)$

we calculate the IS using:

$I S_{1}=\frac{\left(\gamma_{1} m_{11}+\gamma_{2} m_{12}\right)^{2}}{\left(\gamma_{1} m_{11}+\gamma_{2} m_{12}\right)^{2}+\left(\gamma_{2} m_{22}\right)^{2}}$

$I S_{2}=\frac{\left(\gamma_{2} m_{22}\right)^{2}}{\left(\gamma_{1} m_{11}+\gamma_{2} m_{12}\right)^{2}+\left(\gamma_{2} m_{22}\right)^{2}}$

Recent studies show that IS and CS are sensitive to the relative level of noise in each market, they measure a combination of leadership in impounding new information and the relative level of noise in the price series from each market. The measures tend to overstate the price discovery contribution of the less noisy market. An appropriate combination of IS and CS cancels out dependence on noise, Yan and Zivot (2010); Putninš (2013). The combined measure is known as the Information Leadership Share (ILS) which is calculated as:

$I L S_{1}=\frac{\left|\frac{I S_{1}}{I S_{2}} \frac{C S_{2}}{C S_{1}}\right|}{\left|\frac{I S_{1}}{I S_{2}} \frac{C S_{2}}{C S_{1}}\right|+\left|\frac{I S_{2}}{I S_{1}} \frac{C S_{1}}{C S_{2}}\right|}$ and $I L S_{2}=\frac{\left|\frac{I S_{2}}{I S_{1}} \frac{C S_{1}}{C S_{2}}\right|}{\left|\frac{I S_{1}}{I S_{2}} \frac{C S_{2}}{C S_{1}}\right|+\left|\frac{I S_{2}}{I S_{1}} \frac{C S_{1}}{C S_{2}}\right|}$

${ }^{4} \Omega=\left(\begin{array}{cc}\sigma_{1}^{2} & \rho \sigma_{1} \sigma_{2} \\ \rho \sigma_{1} \sigma_{2} & \sigma_{2}^{2}\end{array}\right)$ and its Cholesky factorisation, $\Omega=M M^{\prime}$ 
Table 4

Significant increases in conditional volatility in the short-run after the event.

\begin{tabular}{|c|c|c|c|c|c|c|c|c|c|c|c|}
\hline Company & Event date & $a_{0}$ & $R_{t-1}$ & DJIA & WTI & Avi & $\omega$ & $\alpha$ & $\beta$ & $\gamma$ & $D_{t}$ \\
\hline AFLT & 31 January 2000 & $\begin{array}{l}-0.0002^{* * *} \\
(0.0001)\end{array}$ & $\begin{array}{l}0.0036 \\
(0.004)\end{array}$ & $\begin{array}{l}-0.1486^{* * *} \\
(0.0157)\end{array}$ & $\begin{array}{l}0.0814^{* * * *} \\
(0.0181)\end{array}$ & $\begin{array}{l}0.4434 * * * \\
(0.048)\end{array}$ & $\begin{array}{l}-0.2603^{* * *} \\
(0.0091)\end{array}$ & $\begin{array}{l}0.0034 \\
(0.0136)\end{array}$ & $\begin{array}{l}0.9634 * * * \\
(0.0005)\end{array}$ & $\begin{array}{l}0.1528 * * * \\
(0.0366)\end{array}$ & $\begin{array}{l}0.2628 * * \\
(0.1088)\end{array}$ \\
\hline AFLT & 24 April 2000 & $\begin{array}{l}-0.0004^{*} \\
(0.0003)\end{array}$ & $\begin{array}{l}0.0092 \\
(0.0107)\end{array}$ & $\begin{array}{l}-0.214^{* * *} \\
(0.0493)\end{array}$ & $\begin{array}{l}0.081^{* * *} \\
(0.0109)\end{array}$ & $\begin{array}{l}0.471 * * * \\
(0.0075)\end{array}$ & $\begin{array}{l}-0.9938 * * * \\
(0.015)\end{array}$ & $\begin{array}{l}0.0155 \\
(0.0288)\end{array}$ & $\begin{array}{l}0.8634 * * * \\
(0.0001)\end{array}$ & $\begin{array}{l}0.3029 * * * \\
(0.0344)\end{array}$ & $\begin{array}{l}0.265^{* * *} \\
(0.0412)\end{array}$ \\
\hline AFLT & 01 May 2000 & $\begin{array}{l}-0.0004 \% \\
(0.0002)\end{array}$ & $\begin{array}{l}0.0091 \\
(0.0131)\end{array}$ & $\begin{array}{l}-0.2132^{* * *} \\
(0.0526)\end{array}$ & $\begin{array}{l}0.0808^{* * * *} \\
(0.0116)\end{array}$ & $\begin{array}{l}0.4701 * * * \\
(0.0075)\end{array}$ & $\begin{array}{l}-0.9905^{* * *} \\
(0.015)\end{array}$ & $\begin{array}{l}0.016 \\
(0.0288)\end{array}$ & $\begin{array}{l}0.8638^{* * *} \\
(0.0001)\end{array}$ & $\begin{array}{l}0.3017 * * * \\
(0.0342)\end{array}$ & $\begin{array}{l}0.3063^{* * *} \\
(0.1019)\end{array}$ \\
\hline AFLT & 27 August 2001 & $\begin{array}{l}-0.0004 \\
(0.0003)\end{array}$ & $\begin{array}{l}0.0095 \\
(0.014)\end{array}$ & $\begin{array}{l}-0.2185^{* * *} \\
(0.0539)\end{array}$ & $\begin{array}{l}0.0807^{* * *} \\
(0.0164)\end{array}$ & $\begin{array}{l}0.4739 * * * \\
(0.057)\end{array}$ & $\begin{array}{l}-0.9822^{* * *} \\
(0.0477)\end{array}$ & $\begin{array}{l}0.0134 \\
(0.063)\end{array}$ & $\begin{array}{l}0.865^{* * *} \\
(0.014)\end{array}$ & $\begin{array}{l}0.3016 \\
(0.2331)\end{array}$ & $\begin{array}{l}0.2938^{* *} \\
(0.1247)\end{array}$ \\
\hline AIRF.PA & 15 August 1996 & $\begin{array}{l}-0.0006 \\
(0.0004)\end{array}$ & $\begin{array}{l}-0.0462^{* * *} \\
(0.0167)\end{array}$ & $\begin{array}{l}0.0952 \\
(0.0741)\end{array}$ & $\begin{array}{l}-0.067 * * * \\
(0.0197)\end{array}$ & $\begin{array}{l}0.9138 * * * \\
(0.0634)\end{array}$ & $\begin{array}{l}-0.0007 \\
(0.0007)\end{array}$ & $\begin{array}{l}-0.0139^{* * *} \\
(0.0064)\end{array}$ & $\begin{array}{l}0.9995^{* * *} \\
(0)\end{array}$ & $\begin{array}{l}0.0252^{* * *} \\
(0.0011)\end{array}$ & $\begin{array}{l}0.2558^{* * *} \\
(0.078)\end{array}$ \\
\hline AIRF.PA & 29 August 1996 & $\begin{array}{l}-0.0006 * * \\
(0.0002)\end{array}$ & $\begin{array}{l}-0.0444^{* * *} \\
(0.0116)\end{array}$ & $\begin{array}{l}0.0963^{* *} \\
(0.0379)\end{array}$ & $\begin{array}{l}-0.0662^{* * *} \\
(0.0198)\end{array}$ & $\begin{array}{l}0.907 * * * \\
(0.0647)\end{array}$ & $\begin{array}{l}-0.0024^{* * *} \\
(0.0007)\end{array}$ & $\begin{array}{l}-0.0145^{* *} \\
(0.006)\end{array}$ & $\begin{array}{l}0.9993^{* * *} \\
(0)\end{array}$ & $\begin{array}{l}0.0247 * * * \\
(0.0017)\end{array}$ & $\begin{array}{l}0.274 * * * \\
(0.0747)\end{array}$ \\
\hline ALK & 15 September 2008 & $\begin{array}{l}-0.0001 \\
(0.0002)\end{array}$ & $\begin{array}{l}-0.0513^{* * *} \\
(0.0095)\end{array}$ & $\begin{array}{l}1.0525^{* * *} \\
(0.0918)\end{array}$ & $\begin{array}{l}-0.1832^{* * *} \\
(0.018)\end{array}$ & $\begin{array}{l}0.3261 * * * \\
(0.0354)\end{array}$ & $\begin{array}{l}-0.0673^{* * *} \\
(0.0021)\end{array}$ & $\begin{array}{l}-0.0064 \\
(0.0139)\end{array}$ & $\begin{array}{l}0.9906^{* * *} \\
(0.0001)\end{array}$ & $\begin{array}{l}0.0722 * * * \\
(0.0024)\end{array}$ & $\begin{array}{l}0.2259 * * * \\
(0.0523)\end{array}$ \\
\hline DAL & 12 January 2009 & $\begin{array}{l}-0.0001 \\
(0.0003)\end{array}$ & $\begin{array}{l}0.004 \\
(0.0173)\end{array}$ & $\begin{array}{l}1.1402^{* * *} \\
(0.0502)\end{array}$ & $\begin{array}{l}-0.2078^{* * *} \\
(0.0217)\end{array}$ & $\begin{array}{l}0.2837 * * * \\
(0.06)\end{array}$ & $\begin{array}{l}-0.0172^{* * *} \\
(0.0012)\end{array}$ & $\begin{array}{l}-0.0233^{* * *} \\
(0.0099)\end{array}$ & $\begin{array}{l}0.9973 * * * \\
(0)\end{array}$ & $\begin{array}{l}0.0684 * * * \\
(0.0007)\end{array}$ & $\begin{array}{l}0.1196^{* * *} \\
(0.0423)\end{array}$ \\
\hline LTM.SN & 15 October 1997 & $\begin{array}{l}0.0003^{* *} \\
(0.0001)\end{array}$ & $\begin{array}{l}0.1596^{* * *} \\
(0.015)\end{array}$ & $\begin{array}{l}0.1823^{* * *} \\
(0.0272)\end{array}$ & $\begin{array}{l}-0.0102^{* * *} \\
(0.0035)\end{array}$ & $\begin{array}{l}0.318^{* * *} \\
(0.0254)\end{array}$ & $\begin{array}{l}-0.2531^{* * *} \\
(0.0214)\end{array}$ & $\begin{array}{l}-0.0201 \\
(0.0158)\end{array}$ & $\begin{array}{l}0.9666^{* * *} \\
(0.0025)\end{array}$ & $\begin{array}{l}0.1527 * * * \\
(0.0124)\end{array}$ & $\begin{array}{l}0.3463^{* * *} \\
(0.0701)\end{array}$ \\
\hline PIAa.KA & 06 March 2003 & $\begin{array}{l}-0.0017^{* * *} \\
(0.0004)\end{array}$ & $\begin{array}{l}-0.054^{* * *} \\
(0.0144)\end{array}$ & $\begin{array}{l}-0.0253 \\
(0.0714)\end{array}$ & $\begin{array}{l}0.1169 \\
(0.077)\end{array}$ & $\begin{array}{l}-0.0042 \\
(0.1098)\end{array}$ & $\begin{array}{l}-0.5279 * * \\
(0.263)\end{array}$ & $\begin{array}{l}-0.0035 \\
(0.0145)\end{array}$ & $\begin{array}{l}0.9163^{* * *} \\
(0.0408)\end{array}$ & $\begin{array}{l}0.2365 * * * \\
(0.0596)\end{array}$ & $\begin{array}{l}0.1028^{* *} \\
(0.0423)\end{array}$ \\
\hline THYAO.IS & 15 September 1995 & $\begin{array}{l}0.0004 \\
(0.0003)\end{array}$ & $\begin{array}{l}-0.0218 \\
(0.0214)\end{array}$ & $\begin{array}{l}0.0567 \\
(0.102)\end{array}$ & $\begin{array}{l}-0.0387^{*} \\
(0.0204)\end{array}$ & $\begin{array}{l}0.4474 * * * \\
(0.0891)\end{array}$ & $\begin{array}{l}-0.0334^{* * *} \\
(0.0013)\end{array}$ & $\begin{array}{l}-0.0035 \\
(0.0077)\end{array}$ & $\begin{array}{l}0.9945^{* * *} \\
(0)\end{array}$ & $\begin{array}{l}0.0761 * * * \\
(0.0001)\end{array}$ & $\begin{array}{l}0.1607 * * * \\
(0.0505)\end{array}$ \\
\hline
\end{tabular}

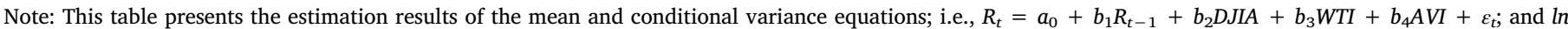

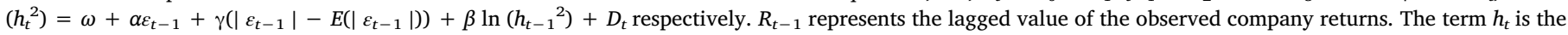

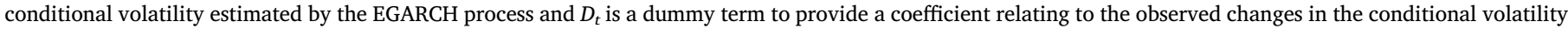

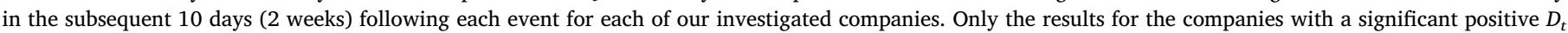

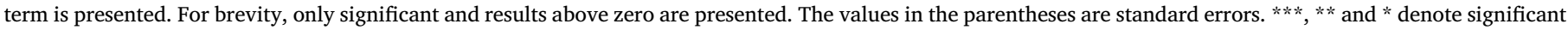
at the $1 \%, 5 \%$ and $10 \%$ level respectively.

Our work on the information share, component share and information leadership share of price discovery sets out to address the final stated hypothesis as to whether there exist substantial changes in information flows between the distressed aviation companies and broad aviation indices in the period after such disasters.

\section{Results}

The first analysed hypothesis investigated as to whether the price response of airlines in the aftermath of aviation disasters has varied substantially. To begin such an analysis, we focus on a number of different characteristics surrounding the behaviour of the share prices of companies that have experienced such aviation disasters. In Fig. 3 we observe the share price return volatility on a daily level of these companies over time between 1995 and 2019. A one-year sample, both sixmonths before and after the incident is presented. We clearly identify that substantially elevated levels of share price volatility on average in the periods incorporating 1995 through 2019, however, there is evidence to suggest that this volatility has somewhat decreased in the period of time thereafter. Throughout each period, there is evidence presented of sharp negative price movements in the days following the aviation disaster, however, as is particularly evident in the periods 2005 through 2019, this is immediately followed by substantial increases in the two-month period after the incident. In Fig. 4 we observe the results of a similar analysis that has been separated by the continent in which the parent company of the airline was located at the time of the incident. For each region analysed, there is substantial evidence of immediate negative responses in each jurisdiction with the exception of South America which is portrayed as quite a volatility market throughout the period analysed. It is Asia and North America that present the most substantial decreases in share price in the days immediately after the date on which the incident occurred. On average, North American airlines experience quite a substantial increase in share price within ten days of the incident.

In Fig. 5 we analyse the cumulative abnormal returns (CARs) over time and in Fig. 6 we observe the same analysis as separated by the region in which the disaster has occurred. The selection of six month windows before and after each event is made solely for presentation purposes. Focusing on the performance of the CARs over time, we observe that there exist sharp under-performance of the companies throughout each of the analysed time periods with the exception of the period between 2000 and 2004. While considering the relative diversification that aviation stocks presented throughout the multiple international financial crises to portfolio investors, the same stocks were very much exposed to shocks in the market for oil (Kristjanpoller \& Concha, 2016; Yun \& Yoon, 2019). There is further evidence that CARs do not appear to behave in a similar manner depending on the market in which the airline stock is traded. South American airlines presented evidence of substantial under-performance when compared to international averages in the period before airline crashes leading to fatality. This identified under-performance continued in the period thereafter. African, European and North American airlines were identified to largely out-perform broad markets by more than $10 \%$, but in the period thereafter, under-performed the same indices by between $6 \%$ and $10 \%$. When considering this information, we can validate $\mathrm{Hy}-$ pothesis 1 , as we clearly identify time-varying and regional differentials between airline share price performance due to aviation disasters.

In the next phase of our analysis, we investigate the changing financial market volatility effects of each individual case analysed. In Table 2 we present the results of each of the individual EGARCH methodologies analysed ${ }^{5}$ Specifically, dummy analysis in the volatility model shows that the largest long-term sustained volatility increase are found to relate to that of six specific events: Event $21(+0.6206)$, event $16(+0.4324)$, event $17(+0.4309)$, event $14(+0.3716)$, event 56 $(+0.2575)$ and event $35(+0.1835)$. In Table 3 we observe the number of companies that experienced a sustained increase in their stock returns' unconditional volatility in the period after each incident. To this effect, we observe as to whether the estimated volatility increases, as

\footnotetext{
${ }^{5}$ For brevity, only significant results are presented here. All results across the entire range of analysed dummy variables (of 1-day, 5-day, 10-day, 20-day, 40day and 60-day duration) are presented in online appendix.
} 
a) EGARCH-calculated volatility based on the number of fatalities that have occurred in each incident

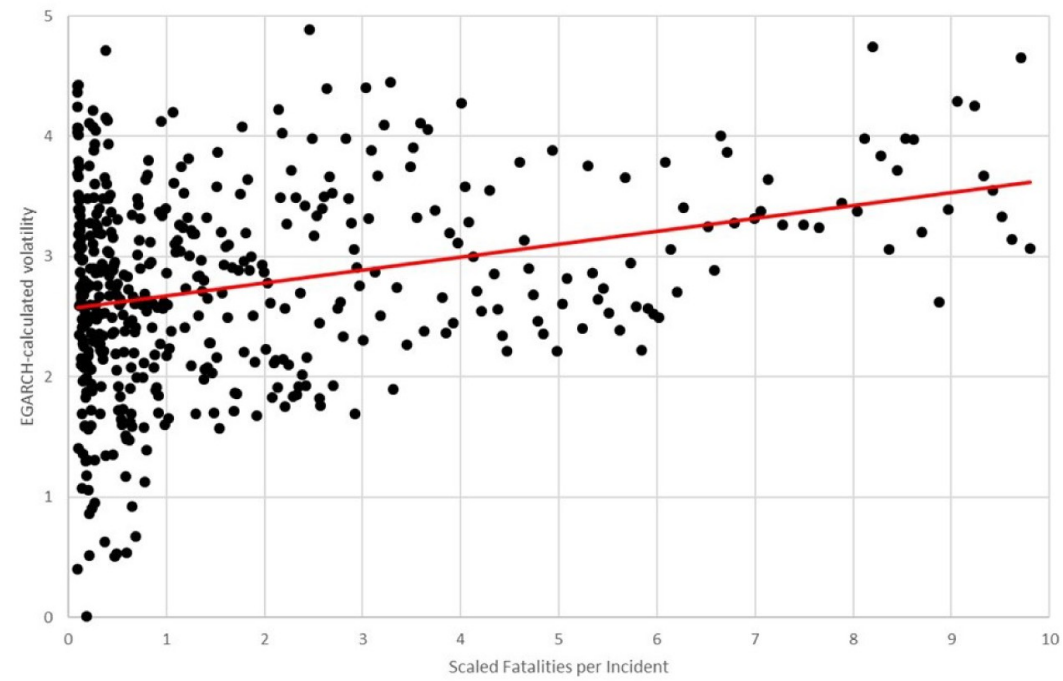

b) EGARCH-calculated volatility over time

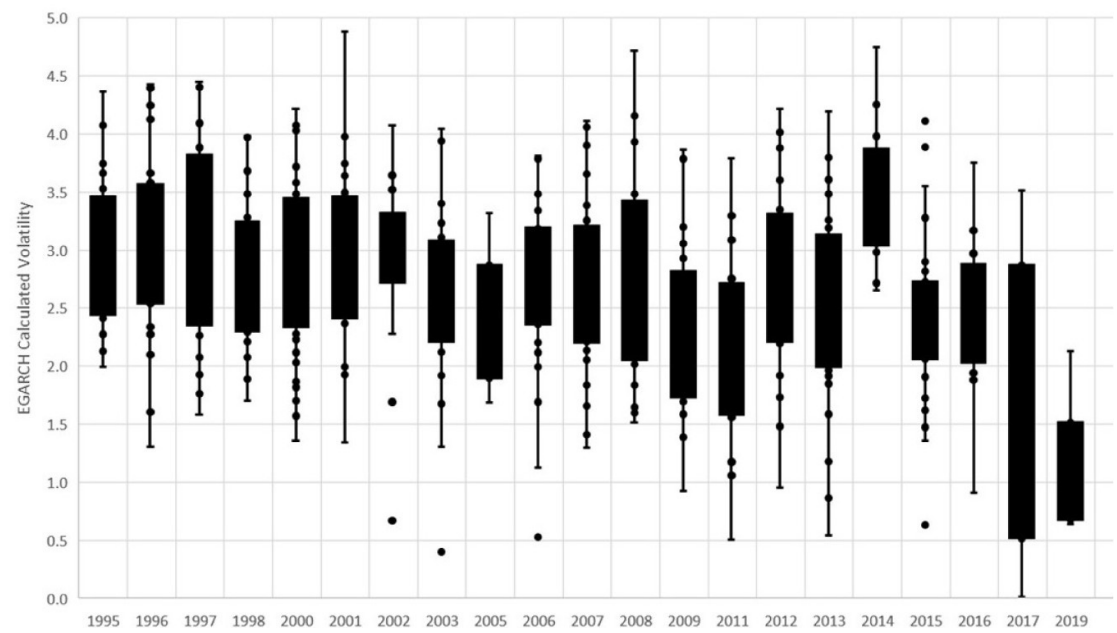

Fig. 7. The relationship between EGARCH-calculated volatility and both the scale and time of the incident.

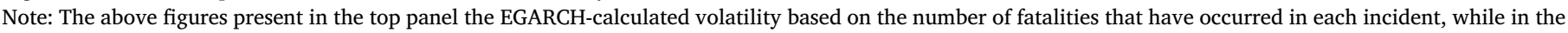
lower panel, the EGARCH-calculated volatility over time.

measured by both the logarithm of daily returns and excess logarithm of daily returns were significantly different to zero in the periods representing ten, twenty, forty and sixty days after the incident. The results are separated between log-returns with a higher variance and excess log-returns with higher variance. Within this context, in both samples analysed, we observe that there are a large number of companies that experience a sharp increase in unconditional volatility in the ten-day period both before and after the aviation incident, indicative of strong short-term effects. However, such effects are found to dissipate in the following windows of investigation, based on twentyday, forty-day and sixty-day windows respectively. Such results indicate that while the shock to unconditional volatility appears to be immediate, there is evidence to suggest that it dissipates and returns to pre-aviation incident levels within sixty days after the event. While focusing on the time-variations of the estimated results Table 4 presents the significant estimates of short-term (denoted to be the ten-day period after the airline disaster) price volatility. We observe that companies that have experienced more recent aviation disasters possess an increased correlation with the DJIA and a decreased correlation over time with other aviation companies as measured by the SPDR S\&P Transportation ETF. Within the models presented in Table 4, we observe the sharp, strongly significant increases in short-term volatility in the period after the aviation disaster as measured by $D_{t}$.
The variants dummy variable duration of the estimated EGARCH methodology allow for the investigation of Hypotheses $\mathrm{H}_{2}$ and $\mathrm{H}_{3}$, which specifically analyse as to whether the price volatility response of the airline disasters appears to depend on the scale of the disaster as measured by the number of fatalities and as to whether such volatility effects have changed over time. Fig. 7 presents the results of these analyses. While utilising the volatility estimates across all cases included in this analysis, we use a scatter-plot to identify the relationship between these dummy variable estimates and that of number of fatalities per incident. The results indicate a clear positive relationship between the two variables, indicating that the estimated EGARCH-volatility appears to be significantly influenced by the scale of the disaster in terms of the fatalities generated. These two specific results enable acceptance of both Hypotheses 2 and 3 as there is clear evidence of a relationship between volatility and incident-severity, while further, such volatility effects are found to changed over time.

In Fig. 8, we specifically analyse as to whether the investigated dynamic correlations have changed over time. To complete such an analysis we have broken the analysis into five year windows of analysis and presented the average dynamic conditional correlation for the sixty day period both before and after each incident. We observe that there were substantial decreased in correlation in the periods after incidents in the period 1995-99, 2000-04 and 2005-09 respectively. However, 
a) $1995-1999$

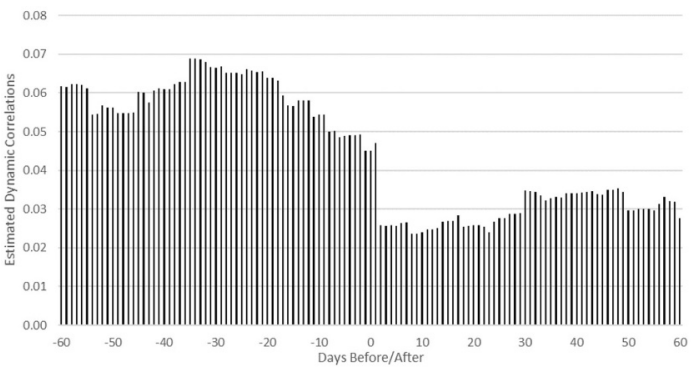

c) $2005-2009$

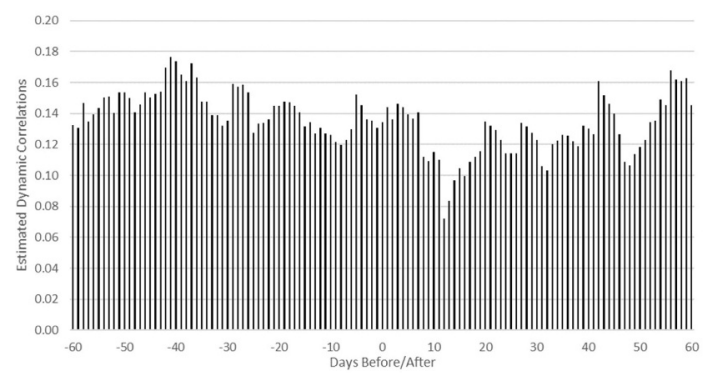

b) $2000-2004$

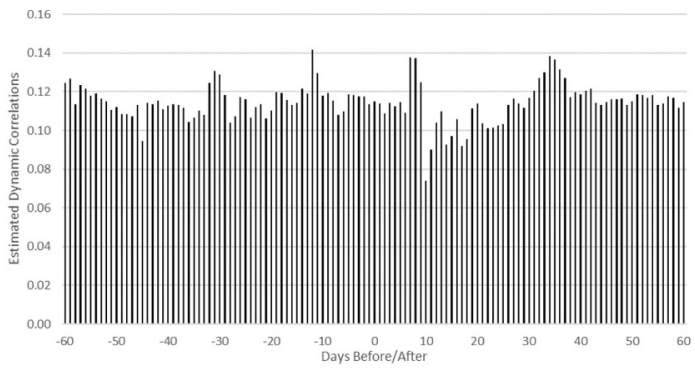

d) $2010-2014$

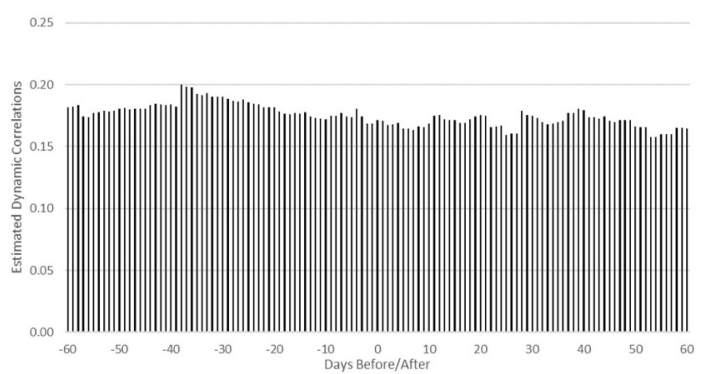

e) 2015-2019

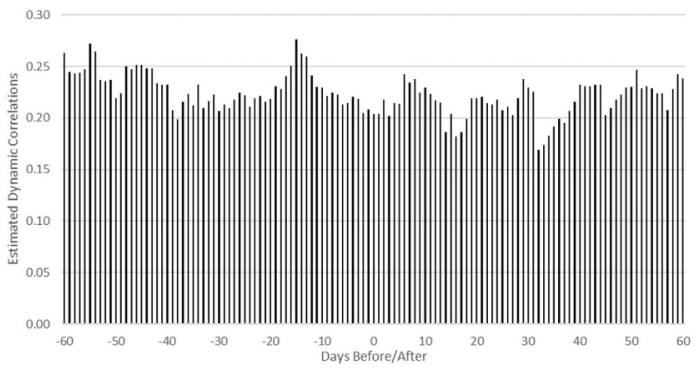

Fig. 8. Dynamic conditional correlations with aviation sector over time due to airline disasters (1995-2019).

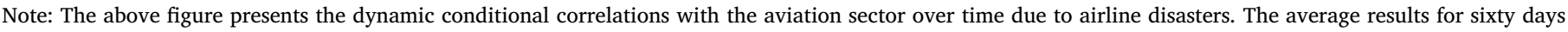
both before and after each incident for presentation purposes.

evidence of such pronounced effects do not appear to occur in the periods between 2010 and 14 and 2015-19. While in Fig. 9 we observe the average dynamic correlation by region in the sixty day periods both before and after the investigated aviation disaster. While crashes in Africa are found to have little of substantial change in the period after, there are substantial changes in dynamic conditional correlation observed for incidents that have occurred in Asia, Europe, and both North and South America respectively. The most substantial effects were observed in South America where the dynamic correlation is found to fall from 0.193 on the date of the incident to fall to 0.048 ten days after the incident. Such results indicate that there are geographical differences to be considered where volatility appears to differ based on the region in which the incident occurs.

In Table 5, we observe the results of the dynamic conditional correlation analysis between the incident company and the selected aviation indices in the aftermath of airline disasters. Such an analysis is used to specifically test Hypothesis $H_{4}$. Two panels are presented in Table 5, where the first presents all dummy coefficients that are found to result in a positive result for the dynamic conditional correlation, while the lower panel presents only significant results. For brevity, only positive results are presented, while negligible results are omitted for presentation purposes only. Each dummy window is presented, based on 1day through 60-day frequencies and an additional analysis which includes the entire sample period after the aviation disaster. While there is a relatively stable number of incidents that present significantly positive volatility through to the broad aviation industry as represented through the twenty-five through twenty-seven incidents that are found to present positive dummy coefficients. For the entire period thereafter, forty-two companies representing $62.7 \%$ of the sample are found to be positive while analysing the entire period after the event. However, while concentrating on significant results only, there is an interesting observation based on the time frame in which the dynamic correlations are found to be significantly positive. Only one event is found to have generated a significantly positive conditional correlation through to the broad aviation indices, however, the effects of this event are found to dissipate before twenty days after the event. While forty events are found to generate significant positive volatility transfer, it appears that such effects become more substantial over time. This could be attributed to improved information being released to the market as to the exact nature and causes of the incident, which could generate profound industrial changes dependent on the nature of the scenarios. Due to the identification of such significant positive correlations, we can state acceptance of Hypothesis $\mathrm{H}_{4}$, namely that individual shocks possess the ability to influence the volatility of the entire aviation index.

The final hypothesis investigates as to whether there exists a substantial change in information flows between the distressed aviation company and broad aviation indices after an airline disaster. In Table 6 we observe the most substantial changes in the flow of information as 
a) Africa

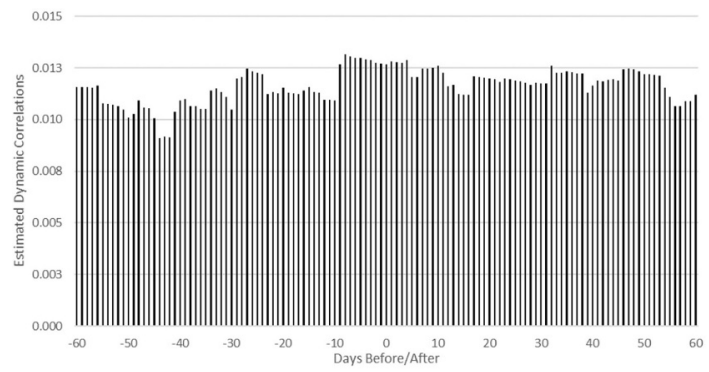

c) Europe

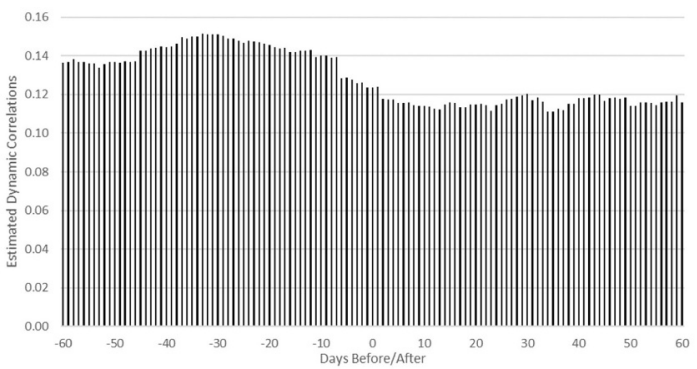

b) Asia

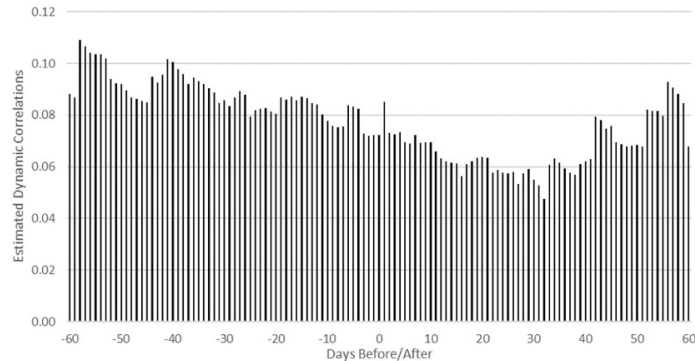

d) North America

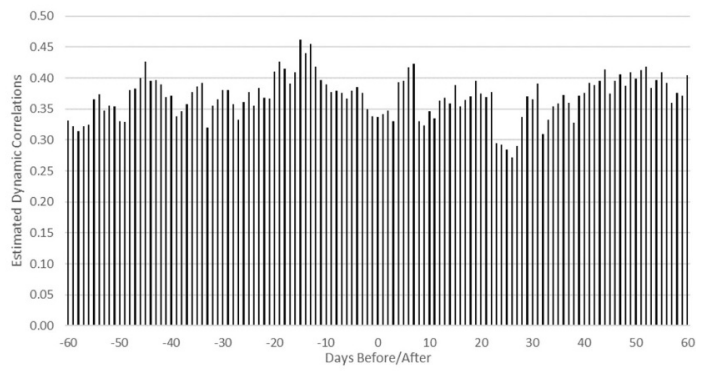

South America

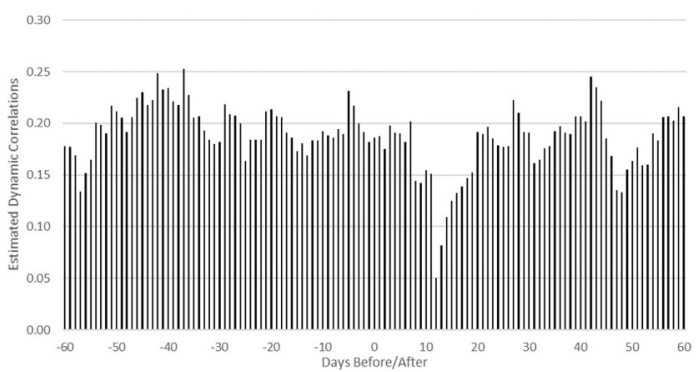

Fig. 9. Dynamic conditional correlations with aviation sector by region due to airline disasters.

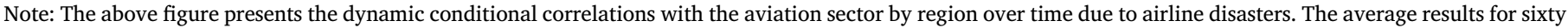
days both before and after each incident for presentation purposes.

measured by the information share, component share and information leadership share of price discovery in the periods both before and after the identified significant incidents. In all cases, there were substantial decreases in information flow identified between the interactions between both the airline and the aviation sector. This indicates that there is a sharp reduction in the flow of information that can be measured by the proportion of the variance in the common efficient price innovations that is explained by innovations in that price series. The permanent component is interpreted as the common efficient price, the temporary component reflects deviations from the efficient price caused by trading fractions. In all cases, there is evidence of a sharp decoupling of information from broad aviation indices upon that of the companies included in the analysis. These results present substantial evidence of a significant decoupling between the airline and other similar companies within the same sector. This adds further support to the differing interactions between market participants and the manner in which information flows between markets, validating the final, fifth hypothesis that there exists substantial decoupling of broad sectoral indices with the airlines that have experienced substantial tragedy.

\section{Concluding comments}

In this paper, we investigate as to whether a number of stylised facts relating to the effects of airline disasters on aviation stocks and contagion effects within the broad sector hold. Using a number of exceptionally detailed databases, we investigate as to whether there exist time-varying and geographical differences in the response mechanisms of investors to aviation disasters, or indeed, has there been a variation of response that could be considered to be correlated to the level of injury and fatality caused by each individual incident. Further, we generate further novelty through the inclusion of analysis that focused on the interlinkages between the incident companies and the broad aviation sector, and indeed the flow of information and price discovery that could be considered to be abnormal when considering pre-disaster averages.

We first clearly identify that substantially elevated levels of share price volatility on average in the periods incorporating 1995 through 2019 , however, there is evidence to suggest that this volatility has somewhat decreased in the periods 2005 through 2019. This indicates that while share price volatility increases while price falls remain substantial, their effects have fallen over time. Further, such effects are found to be substantial when considering geographical differentials, with both North American and South American companies exhibiting the largest negative effects. When analysing cumulative abnormal returns, we observe that there exist sharp under-performance of the companies relative to international exchanges throughout each of the analysed time periods with the exception of the period between 2000 and 2004. There is further evidence that CARs do not appear to behave in a similar manner depending on the market in which the airline stock is traded. South American airlines presented evidence of substantial 
Table 5

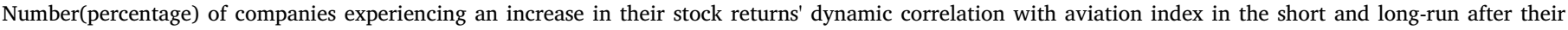
announcements.

\begin{tabular}{|c|c|c|c|c|c|c|c|}
\hline Company & $D^{1 d}$ & $D_{t}^{5 d}$ & $D_{t}^{10 d}$ & $D_{t}^{20 d}$ & $D_{t}^{40 d}$ & $D_{t}^{60 d}$ & $D_{t}^{A l l}$ \\
\hline \multicolumn{8}{|c|}{ Panel A: Positive dummy coefficient } \\
\hline 003490.KS & $1(33.33)$ & $1(33.33)$ & $1(33.33)$ & $1(33.33)$ & $1(33.33)$ & $1(33.33)$ & $1(33.33)$ \\
\hline 2610.TW & $2(66.67)$ & $2(66.67)$ & $2(66.67)$ & $2(66.67)$ & $2(66.67)$ & $3(100)$ & $3(100)$ \\
\hline AC.TO & $1(100)$ & $1(100)$ & $1(100)$ & $1(100)$ & $1(100)$ & $1(100)$ & $0(0)$ \\
\hline AIRA.KL & $1(100)$ & $1(100)$ & $1(100)$ & $1(100)$ & $1(100)$ & $1(100)$ & $0(0)$ \\
\hline AIRF.PA & $1(20)$ & $1(20)$ & $1(20)$ & $1(20)$ & $1(20)$ & $1(20)$ & $4(80)$ \\
\hline ALK & $0(0)$ & $1(100)$ & $1(100)$ & $1(100)$ & $1(100)$ & $1(100)$ & $1(100)$ \\
\hline BA & $2(50)$ & $2(50)$ & $1(25)$ & $1(25)$ & $2(50)$ & $1(25)$ & $4(100)$ \\
\hline LTM.SN & $2(50)$ & $2(50)$ & $2(50)$ & $2(50)$ & $2(50)$ & $2(50)$ & $4(100)$ \\
\hline LUV & $1(100)$ & $1(100)$ & $1(100)$ & $1(100)$ & $1(100)$ & $1(100)$ & $0(0)$ \\
\hline MASM & $2(66.67)$ & $2(66.67)$ & $2(66.67)$ & $2(66.67)$ & $2(66.67)$ & $2(66.67)$ & $1(33.33)$ \\
\hline PIAa.KA & $3(50)$ & $4(66.67)$ & $3(50)$ & $3(50)$ & $2(33.33)$ & $3(50)$ & $6(100)$ \\
\hline SAS.ST & $0(0)$ & $0(0)$ & $0(0)$ & $0(0)$ & $1(50)$ & $1(50)$ & $1(50)$ \\
\hline SEBF.PA & $1(100)$ & $1(100)$ & $1(100)$ & $1(100)$ & $1(100)$ & $1(100)$ & $1(100)$ \\
\hline THYAO.IS & $3(50)$ & $3(50)$ & $3(50)$ & $3(50)$ & $3(50)$ & $3(50)$ & $6(100)$ \\
\hline UAL.O & $2(50)$ & $2(50)$ & $3(75)$ & $2(50)$ & $2(50)$ & $3(75)$ & $0(0)$ \\
\hline ALL & $25(37.31)$ & $27(40.3)$ & $27(40.3)$ & $26(38.81)$ & $25(37.31)$ & $27(40.3)$ & $42(62.69)$ \\
\hline \multicolumn{8}{|c|}{ Panel B: Significant positive dummy coefficient } \\
\hline 2610.TW & $0(0)$ & $0(0)$ & $1(33.33)$ & $2(66.67)$ & $1(33.33)$ & $0(0)$ & $3(100)$ \\
\hline $600,029 . S S$ & $0(0)$ & $1(100)$ & $1(100)$ & $1(100)$ & $1(100)$ & $0(0)$ & $1(100)$ \\
\hline AIRF.PA & $0(0)$ & $1(20)$ & $1(20)$ & $1(20)$ & $1(20)$ & $1(20)$ & $4(80)$ \\
\hline $\mathrm{BA}$ & $0(0)$ & $1(25)$ & $1(25)$ & $1(25)$ & $2(50)$ & $1(25)$ & $4(100)$ \\
\hline DAL & $1(50)$ & $1(50)$ & $1(50)$ & $0(0)$ & $1(50)$ & $1(50)$ & $0(0)$ \\
\hline LTM.SN & $0(0)$ & $2(50)$ & $2(50)$ & $2(50)$ & $2(50)$ & $2(50)$ & $3(75)$ \\
\hline LUV & $0(0)$ & $1(100)$ & $1(100)$ & $1(100)$ & $1(100)$ & $1(100)$ & $0(0)$ \\
\hline MASM & $0(0)$ & $0(0)$ & $0(0)$ & $1(33.33)$ & $1(33.33)$ & 1 (33.33) & 1 (33.33) \\
\hline PIAa.KA & $0(0)$ & $2(33.33)$ & $1(16.67)$ & 1 (16.67) & $1(16.67)$ & $2(33.33)$ & 5 (83.33) \\
\hline THYAO.IS & $0(0)$ & 1 (16.67) & $3(50)$ & $3(50)$ & $3(50)$ & $3(50)$ & $6(100)$ \\
\hline UAL.O & $0(0)$ & $1(25)$ & $0(0)$ & $2(50)$ & $1(25)$ & $2(50)$ & $0(0)$ \\
\hline ALL & 1 (1.49) & $12(17.91)$ & 14 (20.9) & $18(26.87)$ & $16(23.88)$ & $16(23.88)$ & $40(59.7)$ \\
\hline
\end{tabular}

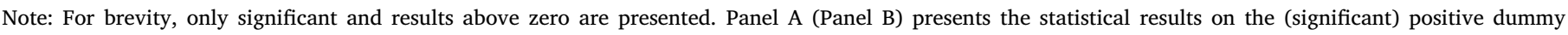

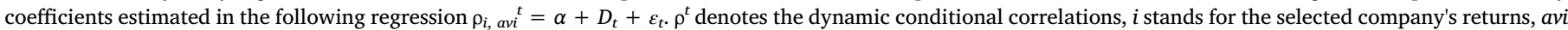

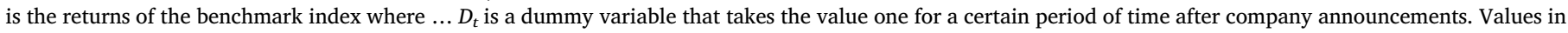

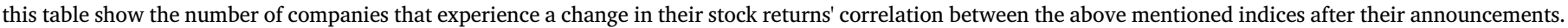

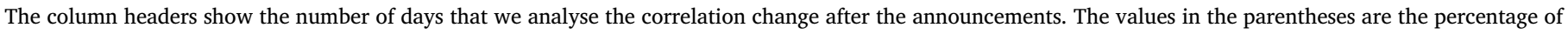
companies within the sub-groups experiencing a change in correlations.

under-performance when compared to international averages in the period before airline crashes leading to fatality, whereas, African, European and North American airlines were identified to largely outperform broad markets by more than $10 \%$, but in the period thereafter, under-performed the same indices by between $6 \%$ and $10 \%$. When considering our EGARCH analysis, we observe that there are a large number of companies that experience a sharp increase in unconditional volatility in the ten-day period both before and after the aviation incident, indicative of strong short-term effects. However, such effects are found to dissipate in the following windows of investigation, based on twenty-day, forty-day and sixty-day windows respectively. Such results indicate that while the shock to unconditional volatility appears to be immediate, there is evidence to suggest that it dissipates and returns to pre-aviation incident levels within sixty days after the event. Further, our results indicate that there exists a clear positive relationship between the two variables, indicating that the estimated EGARCH-volatility appears to be significantly influenced by the scale of the disaster in terms of the fatalities generated. Within this context, our research finds that there exist regional and time-varying effects both in terms of volatility and share price response. Further, such share price volatility is found to be directly responsive to the severity of each incident. This can perhaps be explained by the presence of improved information flows through financial markets in the later years analysed within the sample period.

Further, when considering the contagion effects of volatility and the flow of information and price discovery between the incident company and the broad aviation sector, we find that there were substantial decreased in dynamic conditional correlations during incidents that occurred in the periods 1995-99, 2000-04 and 2005-09 respectively. However,evidence of such pronounced effects do not appear to occur in the periods between 2010 and 14 and 2015-19. Further, crashes in Africa are found to have little of substantial change in the period after, there are substantial changes in dynamic conditional correlation observed for incidents that have occurred in Asia, Europe, and both North and South America respectively. Further, for every case analysed we find that there were substantial decreases in information flow identified between the interactions between both the airline and the aviation sector. This indicates that there is a permanent disruption to the flow of information and price discovery channels that would have traditional have existed in the period prior to the aviation disaster. That is, while companies attempt to return to any form of perceived normality in the period after an aviation disaster, investors appear to treat such companies in a different capacity to industrial peers on a permanent basis. It would be quite interesting for future research to investigate as to whether similar effects area found to permeate throughout the entire supply chain relating to goods an services that are provided to the aviation industry.

Our research has a series of relevant policy implications. Market sensitivity to such sudden, catastrophic shocks such as those related to aviation disasters can of course be considered to be exceptionally negative with regards to expected investor response. However, there has been considerable reservations about the implicit role that social media and the spread of misinformation, or malicious information can have in the aftermath of such events. Much of the spread of such information usually surrounds speculation based on the cause and responsibility attributed to the incident. We feel that analysis and policy review 
Table 6

Price Discovery differentials between aviation companies and the entire sector both before and after aviation disasters.

\begin{tabular}{|c|c|c|c|c|c|c|c|c|c|c|c|}
\hline Event ID & IS pre & CS pre & ILS pre & Lags & IS post & CS post & ILS post & $\Delta \mathrm{IS}$ & $\Delta$ IS-r & $\Delta \mathrm{CS}$ & $\Delta \mathrm{ILS}$ \\
\hline \multirow[t]{2}{*}{1} & 0.7071 & 0.9634 & 0.9715 & 5 & 0.5917 & 0.9750 & 0.9719 & 7 & -0.1154 & 0.0116 & 0.0004 \\
\hline & 0.2929 & 0.0366 & 0.0285 & & 0.4083 & 0.0250 & 0.0281 & & & & \\
\hline \multirow[t]{2}{*}{2} & 0.9002 & 0.9181 & 0.9587 & 4 & 0.6159 & 0.5148 & 0.9667 & 85 & -0.2843 & -0.4033 & 0.0080 \\
\hline & 0.0998 & 0.0819 & 0.0413 & & 0.3841 & 0.4852 & 0.0333 & & & & \\
\hline \multirow[t]{2}{*}{3} & 0.9711 & 0.8329 & 0.9737 & 4 & 0.9128 & 0.6296 & 0.9377 & 90 & -0.0583 & -0.2033 & -0.0360 \\
\hline & 0.0289 & 0.1671 & 0.0263 & & 0.0872 & 0.3704 & 0.0623 & & & & \\
\hline \multirow[t]{2}{*}{4} & 0.7875 & 0.9750 & 0.9676 & 2 & 0.5974 & 0.5835 & 0.9719 & 7 & -0.1901 & -0.3915 & 0.0043 \\
\hline & 0.2125 & 0.0250 & 0.0324 & & 0.4026 & 0.4165 & 0.0281 & & & & \\
\hline \multirow[t]{2}{*}{6} & 0.9178 & 0.9747 & 0.9735 & 2 & 0.6136 & 0.9439 & 0.9572 & 5 & -0.3041 & -0.0308 & -0.0163 \\
\hline & 0.0822 & 0.0253 & 0.0265 & & 0.3864 & 0.0561 & 0.0428 & & & & \\
\hline \multirow[t]{2}{*}{7} & 0.8740 & 0.9650 & 0.9729 & 2 & 0.5678 & 0.9744 & 0.9718 & 7 & -0.3062 & 0.0094 & -0.0011 \\
\hline & 0.1260 & 0.0350 & 0.0271 & & 0.4322 & 0.0256 & 0.0282 & & & & \\
\hline \multirow[t]{2}{*}{8} & 0.9741 & 0.8921 & 0.9748 & 2 & 0.6230 & 0.9473 & 0.9560 & 5 & -0.3511 & 0.0552 & -0.0188 \\
\hline & 0.0259 & 0.1079 & 0.0252 & & 0.3770 & 0.0527 & 0.0440 & & & & \\
\hline \multirow[t]{2}{*}{9} & 0.9460 & 0.9146 & 0.9739 & 2 & 0.5840 & 0.9749 & 0.9718 & 7 & -0.3620 & 0.0603 & -0.0020 \\
\hline & 0.0540 & 0.0854 & 0.0261 & & 0.4160 & 0.0251 & 0.0282 & & & & \\
\hline 11 & 0.9439 & 0.8982 & 0.9565 & 4 & 0.5846 & 0.8982 & 0.9666 & 85 & -0.3593 & 0.0000 & 0.0101 \\
\hline & 0.0561 & 0.1018 & 0.0435 & & 0.4154 & 0.1018 & 0.0334 & & & & \\
\hline 14 & 0.9432 & 0.8564 & 0.9566 & 4 & 0.5105 & 0.5563 & 0.9657 & 85 & -0.4327 & -0.3001 & 0.0091 \\
\hline & 0.0568 & 0.1436 & 0.0434 & & 0.4895 & 0.4437 & 0.0343 & & & & \\
\hline 15 & 0.9214 & 0.9352 & 0.9391 & 4 & 0.4914 & 0.8192 & 0.9225 & 90 & -0.4300 & -0.1160 & -0.0166 \\
\hline & 0.0786 & 0.0648 & 0.0609 & & 0.5086 & 0.1808 & 0.0775 & & & & \\
\hline 16 & 0.9244 & 0.8358 & 0.9396 & 4 & 0.6597 & 0.8142 & 0.9517 & 90 & -0.2647 & -0.0215 & 0.0121 \\
\hline & 0.0756 & 0.1642 & 0.0604 & & 0.3403 & 0.1858 & 0.0483 & & & & \\
\hline 17 & 0.9229 & 0.8625 & 0.9394 & 4 & 0.6215 & 0.8167 & 0.9477 & 90 & -0.3014 & -0.0458 & 0.0083 \\
\hline & 0.0771 & 0.1375 & 0.0606 & & 0.3785 & 0.1833 & 0.0523 & & & & \\
\hline 18 & 0.9273 & 0.9596 & 0.9401 & 4 & 0.5963 & 0.8093 & 0.9651 & 90 & -0.3310 & -0.1503 & 0.0250 \\
\hline & 0.0727 & 0.0404 & 0.0599 & & 0.4037 & 0.1907 & 0.0349 & & & & \\
\hline 21 & 0.9615 & 0.9668 & 0.9741 & 3 & 0.6238 & 0.9483 & 0.9558 & 5 & -0.3377 & -0.0186 & -0.0184 \\
\hline & 0.0385 & 0.0332 & 0.0259 & & 0.3762 & 0.0517 & 0.0442 & & & & \\
\hline 22 & 0.9288 & 0.8067 & 0.9403 & 3 & 0.8226 & 0.6339 & 0.9573 & 90 & -0.1062 & -0.1728 & 0.0170 \\
\hline & 0.0712 & 0.1933 & 0.0597 & & 0.1774 & 0.3661 & 0.0427 & & & & \\
\hline 23 & 0.9274 & 0.8093 & 0.9401 & 3 & 0.7307 & 0.7390 & 0.9595 & 90 & -0.1967 & -0.0703 & 0.0195 \\
\hline & 0.0726 & 0.1907 & 0.0599 & & 0.2693 & 0.2610 & 0.0405 & & & & \\
\hline 24 & 0.9284 & 0.8076 & 0.9402 & 3 & 0.7333 & 0.7374 & 0.9595 & 90 & -0.1951 & -0.0701 & 0.0193 \\
\hline & 0.0716 & 0.1924 & 0.0598 & & 0.2667 & 0.2626 & 0.0405 & & & & \\
\hline 25 & 0.9265 & 0.8108 & 0.9399 & 3 & 0.6434 & 0.8159 & 0.9612 & 90 & -0.2831 & 0.0051 & 0.0213 \\
\hline & 0.0735 & 0.1892 & 0.0601 & & 0.3566 & 0.1841 & 0.0388 & & & & \\
\hline 32 & 0.8134 & 0.7685 & 0.9733 & 2 & 0.5560 & 0.1794 & 0.9735 & 15 & -0.2575 & -0.5891 & 0.0002 \\
\hline & 0.1866 & 0.2315 & 0.0267 & & 0.4440 & 0.8206 & 0.0265 & & & & \\
\hline 36 & 0.9728 & 0.9737 & 0.9616 & 2 & 0.6254 & 0.8041 & 0.9720 & 7 & -0.3474 & -0.1697 & 0.0104 \\
\hline & 0.0272 & 0.0263 & 0.0384 & & 0.3746 & 0.1959 & 0.0280 & & & & \\
\hline 37 & 0.9420 & 0.7798 & 0.9424 & 3 & 0.8193 & 0.7798 & 0.9691 & 90 & -0.1227 & 0.0000 & 0.0267 \\
\hline & 0.0580 & 0.2202 & 0.0576 & & 0.1807 & 0.2202 & 0.0309 & & & & \\
\hline 38 & 0.9434 & 0.7770 & 0.9426 & 3 & 0.7052 & 0.7250 & 0.9610 & 90 & -0.2382 & -0.0521 & 0.0184 \\
\hline & 0.0566 & 0.2230 & 0.0574 & & 0.2948 & 0.2750 & 0.0390 & & & & \\
\hline 46 & 0.9381 & 0.9854 & 0.9417 & 64 & 0.5591 & 0.9728 & 0.7368 & 90 & -0.3790 & -0.0125 & -0.2049 \\
\hline & 0.0619 & 0.0146 & 0.0583 & & 0.4409 & 0.0272 & 0.2632 & & & & \\
\hline 48 & 0.9716 & 0.9725 & 0.9744 & 70 & 0.6099 & 0.9423 & 0.9577 & 5 & -0.3617 & -0.0302 & -0.0167 \\
\hline & 0.0284 & 0.0275 & 0.0256 & & 0.3901 & 0.0577 & 0.0423 & & & & \\
\hline 49 & 0.9675 & 0.9731 & 0.9636 & 75 & 0.5510 & 0.7525 & 0.9717 & 7 & -0.4165 & -0.2206 & 0.0081 \\
\hline & 0.0325 & 0.0269 & 0.0364 & & 0.4490 & 0.2475 & 0.0283 & & & & \\
\hline 52 & 0.9301 & 0.9604 & 0.9405 & 85 & 0.5494 & 0.9604 & 0.8984 & 90 & -0.3807 & 0.0000 & -0.0420 \\
\hline & 0.0699 & 0.0396 & 0.0595 & & 0.4506 & 0.0396 & 0.1016 & & & & \\
\hline 54 & 0.9368 & 0.7322 & 0.9415 & 92 & 0.7852 & 0.7322 & 0.9578 & 90 & -0.1516 & 0.0000 & 0.0163 \\
\hline & 0.0632 & 0.2678 & 0.0585 & & 0.2148 & 0.2678 & 0.0422 & & & & \\
\hline 55 & 0.9376 & 0.9145 & 0.9416 & 92 & 0.5050 & 0.9145 & 0.9616 & 90 & -0.4326 & 0.0000 & 0.0200 \\
\hline & 0.0624 & 0.0855 & 0.0584 & & 0.4950 & 0.0855 & 0.0384 & & & & \\
\hline 56 & 0.9620 & 0.9451 & 0.9331 & 92 & 0.6174 & 0.9396 & 0.9568 & 5 & -0.3446 & -0.0054 & 0.0237 \\
\hline & 0.0380 & 0.0549 & 0.0669 & & 0.3826 & 0.0604 & 0.0432 & & & & \\
\hline 57 & 0.9371 & 0.9537 & 0.9416 & 92 & 0.5059 & 0.9537 & 0.9612 & 90 & -0.4312 & 0.0000 & 0.0196 \\
\hline & 0.0629 & 0.0463 & 0.0584 & & 0.4941 & 0.0463 & 0.0388 & & & & \\
\hline 58 & 0.9451 & 0.9109 & 0.9615 & 92 & 0.8256 & 0.7708 & 0.9711 & 8 & -0.1194 & -0.1401 & 0.0096 \\
\hline & 0.0549 & 0.0891 & 0.0385 & & 0.1744 & 0.2292 & 0.0289 & & & & \\
\hline 60 & 0.8416 & 0.9606 & 0.9720 & 92 & 0.5497 & 0.9731 & 0.9717 & 7 & -0.2919 & 0.0125 & -0.0003 \\
\hline & 0.1584 & 0.0394 & 0.0280 & & 0.4503 & 0.0269 & 0.0283 & & & & \\
\hline 61 & 0.9726 & 0.9743 & 0.9503 & 89 & 0.8492 & 0.5982 & 0.9603 & 85 & -0.1234 & -0.3761 & 0.0101 \\
\hline & 0.0274 & 0.0257 & 0.0497 & & 0.1508 & 0.4018 & 0.0397 & & & & \\
\hline 64 & 0.7523 & 0.9694 & 0.9720 & 2 & 0.5776 & 0.9748 & 0.9718 & 7 & -0.1747 & 0.0054 & -0.0002 \\
\hline & 0.2477 & 0.0306 & 0.0280 & & 0.4224 & 0.0252 & 0.0282 & & & & \\
\hline
\end{tabular}

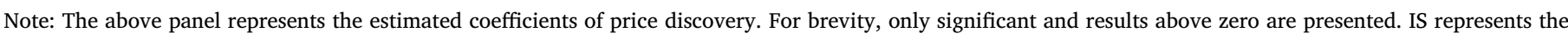

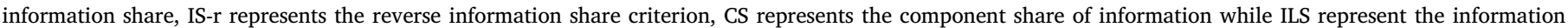

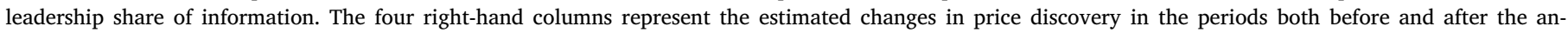
nouncements of name changing processes. 
surrounding high-frequency financial market data paired with that of social media data would be considered a worthy direction of future research. While our research presents evidence that financial markets are guided by better quality information through the development of social media, it should also be considered that the presence of such improved efficiency could in fact manifest in side-effects such as an ability to profit from the spread of false information, not only generating further undue distress on the companies and families involved in such tragedy, but also hindering the efforts of rescue teams while further inspiring other market participants who do not fear current regulatory and policing efforts.

\section{References}

Assaf, A. (2009). Are U.S. airlines really in crisis? Tourism Management, 30(6), 916-921. Barrett, W. B., Heuson, A. J., Kolb, R. W., \& Schropp, G. H. (1987). The adjustment of stock prices to completely unanticipated events. Financial Review, 22(4), 345-354.

Berghofer, B., \& Lucey, B. (2014). Fuel hedging, operational hedging and risk exposure Evidence from the global airline industry. International Review of Financial Analysis, 34, 124-139.

Bollerslev, T. (1986). Generalized autoregressive conditional heteroskedasticity. Journal of Econometrics, 31, 307-327.

Borenstein, S., \& Zimmerman, M. B. (1988). Market incentives for safe commercial airline operation. The American Economic Review, 913-935.

Carpentier, C., \& Suret, J.-M. (2015). Stock market and deterrence effect: A mid-run analysis of major environmental and non-environmental accidents. Journal of Environmental Economics and Management, 71, 1-18.

Carter, D., \& Simkins, B. (2004). The market's reaction to unexpected, catastrophic events: The case of airline stock returns and the September 11th attacks. Quarterly Review of Economics and Finance, 44(4), 539-558.

Carvalho, C., Klagge, N., \& Moench, E. (2011). The persistent effects of a false news shock. Journal of Empirical Finance, 18(4), 597-615.

Chance, D., \& Ferris, S. (1987). The effect of aviation disasters on the air transport industry. A financial market perspective. Journal of Transport Economics Policy, 21(2), $151-166$.

Chuang, I.-Y., Chiu, Y.-C., \& Edward Wang, C. (2008). The performance of asian airlines in the recent financial turmoil based on var and modified sharpe ratio. Journal of Air Transport Management, 14(5), 257-262.

Corbet, S., Gurdgiev, C., \& Meegan, A. (2018). Long-term stock market volatility and the influence of terrorist attacks in Europe. Quarterly Review of Economics and Finance, 68, 118-131.

Corbet, S., O'Connell, J., Efthymiou, M., Guiomard, C., \& Lucey, B. (2019). The impact of terrorism on European tourism. Annals of Tourism Research, 75, 1-17.

Dillon, R., Johnson, B., \& Pate-Cornell, M. (1999). Risk assessment based on financial data: Market response to airline accidents. Risk Analysis, 19(3), 473-486.

Engle, R. (2002). Dynamic conditional correlation: A simple class of multivariate generalized autoregressive conditional heteroskedasticity models. Journal of Business and Economic Statistics, 20(3), 339-350.
Francis, G., Dennis, N., Ison, S., \& Humphreys, I. (2007). The transferability of the lowcost model to long-haul airline operations. Tourism Management, 28(2), 391-398.

Gonzalo, J., \& Granger, C. (1995). Estimation of common long-memory components in cointegrated systems. Journal of Business \& Economic Statistics, 13(1), 27-35.

Hasbrouck, J. (1995). One security, many markets: Determining the contributions to price discovery. Journal of Finance, 50(4), 1175-1199.

Hauptfleisch, M., Putniņš, T. J., \& Lucey, B. (2016). Who sets the price of gold? London or New York. Journal of Futures Markets, 36(6), 564-586.

Ho, J., Qiu, M., \& Tang, X. (2013). Do airlines always suffer from crashes? Economics Letters, 118(1), 113-117.

Hung, J.-H., \& Liu, Y.-C. (2005). An examination of factors influencing airline beta values. Journal of Air Transport Management, 11(4), 291-296.

Kaplanski, G., \& Levy, H. (2010). Sentiment and stock prices: The case of aviation disasters. Journal of Financial Economics, 95(2), 174-201.

Kim, H., \& Gu, Z. (2004). Impact of the $9 / 11$ terrorist attacks on the return and risk of airline stocks. Tourism and Hospitality Research, 5(2), 150-163.

Kolaric, S., \& Schiereck, D. (2016). Are stock markets efficient in the face of fear? Evidence from the terrorist attacks in Paris and Brussels. Finance Research Letters, 18, 306-310.

Krieger, K., \& Chen, D. (2015). Post-accident stock returns of aircraft manufacturers based on potential fault. Journal of Air Transport Management, 43, 20-28.

Kristjanpoller, W., \& Concha, D. (2016). Impact of fuel price fluctuations on airline stock returns. Applied Energy, 178, 496-504.

Lee, J.-S., \& Jang, S. (2007). The systematic-risk determinants of the us airline industry. Tourism Management, 28(2), 434-442.

Li, C.-W., Phun, V. K., Suzuki, M., \& Yai, T. (2015). The effects of aviation accidents on public perception toward an airline. Journal of the Eastern Asia Society for Transportation Studies, 11, 2347-2362.

Luo, X. (2007). Consumer negative voice and firm-idiosyncratic stock returns. Journal of Marketing, 71(3), 75-88.

Mitchell, M. L., \& Maloney, M. T. (1989). Crisis in the cockpit? the role of market forces in promoting air travel safety. The Journal of Law and Economics, 32(2, Part 1), 329-355.

Nethercutt, L., \& Pruitt, S. (1997). Touched by tragedy: Capital market lessons from the crash of valujet flight 592. Economics Letters, 56(3), 351-358.

Noronha, G., \& Singal, V. (2004). Financial health and airline safety. Managerial and Decision Economics, 25(1), 1-16.

Putninš, T. J. (2013). What do price discovery metrics really measure? Journal of Empirical Finance, 23, 68-83.

Treanor, S., Rogers, D., Carter, D., \& Simkins, B. (2014). Exposure, hedging, and value: New evidence from the U.S. airline industry. International Review of Financial Analysis, 34, 200-211.

Walker, T., Thiengtham, D., \& Lin, M. (2005). On the performance of airlines and airplane manufacturers following aviation disasters. Canadian Journal of Administrative Sciences, 22(1), 21-34.

Walker, T., Walker, M., Thiengtham, D., \& Pukthuanthong, K. (2014). The role of aviation laws and legal liability in aviation disasters: A financial market perspective. International Review of Law and Economics, 37, 51-65.

Yan, B., \& Zivot, E. (2010). A structural analysis of price discovery measures. Journal of Financial Markets, 13(1), 1-19.

Yun, X., \& Yoon, S.-M. (2019). Impact of oil price change on airline's stock price and volatility: Evidence from China and South Korea. Energy Economics, 78, 668-679. 